\section{EL QUINDÍO SOBRE SU PASADO Y PRESENTE FRENTE A LOS OBJETIVOS DEL MILENIO.}

\author{
Quindio State: Its Past And Present On The Millenium Project \\ Goals.
}

Alvaro Alfonso Fernández ${ }^{1}$

Mauricio Ramírez Gaona²

Palabras clave: Planes de gobierno, Objetivos de desarrollo del Milenio, proyecto político.

Keywords: Government plans, Millennium Development Goals (MDG), political project.

\section{Resumen}

El trabajo que se presenta a continuación, responde al llamado desde la Universidad Autónoma de Manizales para situar en perspectiva el proyecto político gubernamental en la Eco región del Eje Cafetero, frente a los Objetivos de Desarrollo del Milenio, y en este caso, del Departamento del Quindío y la nueva administración departamental

\section{Abstract}

This paper aims at responding to the call from the Autonoma University of Manizales to situate in perspective the governmental political project, carried out in the Ecoregion of the Coffee Belt before the Millennium Development Goals (MDG), particularly in the state of Quindío and the new state administration ${ }^{3}$.

Entre los departamentos de la Eco región cafetera, el Quindío, por las particularidades de sus dinámicas económica (mayor dependencia del café, y el renglón emergente del turismo, altamente selectivo y focalizado); social (más bajo nivel asociativo, como en el llamado capital humano y desistitucionalización normativa); político (combinación entre débil masa crítica de su estructura política en los niveles regional y nacional, con la contracción severa de los programas de la Federación Nacional de Cafeteros en lo local), y sus consecuencias en un desempleo sostenido, un PIB regresivo en el contexto nacional, desindustrialización, y tercerización forzada, y a pesar de incorporar de manera explícita en el Plan de Desarrollo Departamental las Metas del Milenio, aunque con alguna vaguedad, es el departamento que mayores dificultades enfrenta para satisfacer los Objetivos del Milenio, pero no homogéneo para todos, en tanto, por ejemplo, en el área de la salud para la atención materna e infantil, como en otras áreas
1 Docente Programa Trabajo Social U.Q. Antropólogo Universidad Nacional. Especialista investigación sociológica Universidad. del Valle; Maestría terminada en Sociología Universidad del Valle.

2 Trabajador Social Universidad del Quindío; Grupo de Investigación en Desarrollo Universidad del Quindío

3 Traducido por Mónica Naranjo Ruiz, integrante grupo de investigación CITERM. Revisado por el nativo Kevin P. Guzzo.

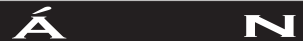

Universidad Autónoma de Manizales 
particulares de vigilancia, se ha avanzado. Objetivos mismos que como de manera somera se presenta, han implicado, para su protocolización, como en el caso de la Equidad de Género, retrocesos respecto de los acuerdos y logros internacionales, logros y acuerdos que tributan además hacia la fundamentación de el Desarrollo Humano, bandera del UNDP; o como el último objetivo y quizás soporte básico de los demás, de un acuerdo internacional (y subniveles hacia abajo) para el desarrollo, dejado a la deriva de las conductas más morales y retóricas de los poderes políticos y económicos, en medio de los ritmos de competencias descarnadas y sin cuartel. Secundariamente, los objetivos a ras acordados, se pueden sobreentender como diferenciales según los países y continentes, para variar las metas hacia exigencias mayores allí donde las dinámicas "civilizatorias", aún por inercia, han estabilizado políticas de estandarización masiva, como en el área - entre otras- de la educación básica.

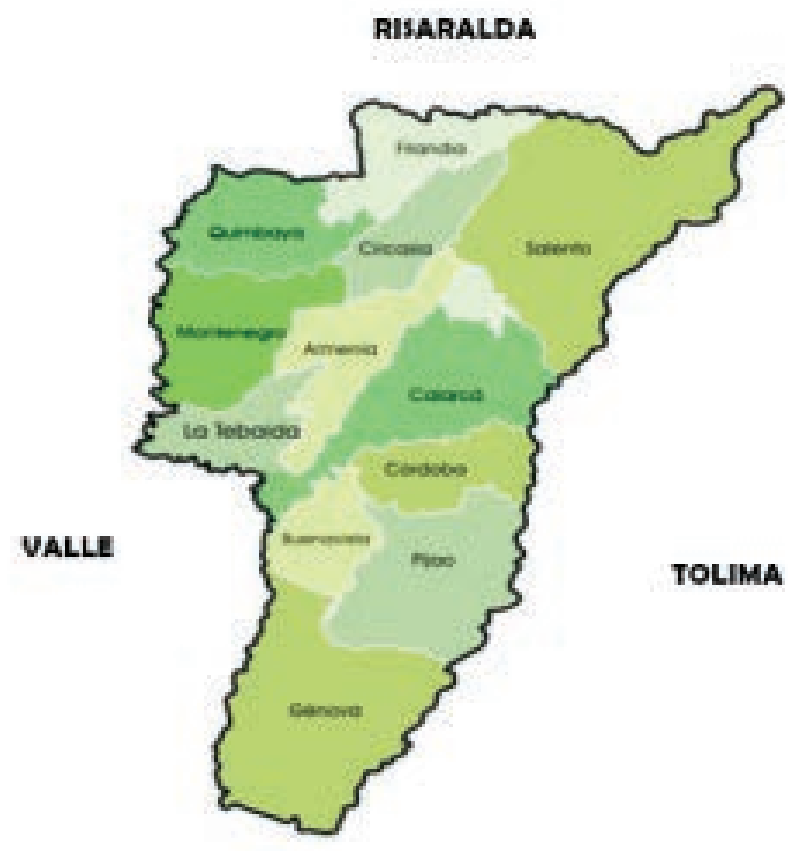

\section{Presentación}

\section{Aspectos Generales}

Mapa tomado del actual Plan de Desarrollo Departamental

El actual departamento del Quindío, antes parte de Caldas, se creó y organizó con la expedición por el Congreso de Colombia, de la Ley 2a de enero 07 de 1966, con capital en Armenia, y conformada por 10 Municipios de los 12 de la actualidad: Armenia, Calarcá, Circasia, Filandia, Génova, La Tebaida, Montenegro, Pijao, Quimbaya y Salento, con los límites que tienen los mencionados Municipios. El Municipio de Buenavista será creado por la Ordenanza 29 del 26 de Noviembre de 1966, segregado de Pijao; y Córdoba a través de la Ordenanza 22 del 26 de noviembre de 1966, segregado de Calarcá.

\section{A $\quad \mathbf{N}$


Los municipios se distribuyen en 3 zonas geográficas identificadas por el tipo de relieve: Zona Plana: Montenegro, Quimbaya y La Tebaida. Zona de Piedemonte con zonas de montaña: Armenia, Calarcá, Circasia y Filandia. Zona de Montaña: Salento, Córdoba, Buenavista, Pijao y Génova.

La ubicación de estos municipios en estas zonas ha significado en la historia departamental, especies de recursos logísticos, estratégicos y de capital para diversos actores, generando formas de distribución geográfica de intereses, y disputas o penetración de capitales y organizaciones, cuya ubicación les va asegurando una mayor fortaleza relativa.

De igual manera, observado en conjunto, la ubicación del Quindío, y de la Ecoregión, al centro del país, resulta estratégica también por su centralidad en el llamado triangulo de oro, donde se destaca al Quindío en particular, como puerta de entrada desde el pacífico al interior del país, por el paso en la cordillera central que conduce a los departamentos de Tolima, a Cundinamarca y al Distrito Capital de Bogotá, con la llamada vía de la Línea, que atraviesa toda la cordillera con los municipios de Calarcá y San Bonifacio de Ibagué en cada uno de sus extremos viales. Dicha carretera es eje vertebral de toda la economía del país, participando, con el Eje cafetero y el Valle, en los megaproyectos de las dobles calzadas, el Túnel de la Línea, Los viaductos en la misma carretera, y a futuro, el desarrollo del Puerto de Tribugá en el Pacífico, como parte de un paquete mayor de megaproyectos de diverso tipo: desde los de infraestructura de comunicaciones, hasta puertos de paso de redistribución de producción, parque temáticos, infrestructura hotelera, entre otros.

El significado estratégico de ubicación, como de la fragilidad de la vía cordillerana principal de la Línea como punto sensible que puede afectar la economía nacional, ha hecho que el departamento tenga un número inusual de fuerza pública y agencias de seguridad del Estado, así como de los llamados informantes civiles, reclutados por el gobierno de Uribe.

La proyección de población del departamento, a partir del censo de 2005 se presenta en el siguiente cuadro:

\begin{tabular}{|l|c|c|c|}
\hline \multirow{2}{*}{ Municipios } & \multicolumn{3}{|c|}{ Población 2008 } \\
& \multicolumn{2}{|c|}{ (Proyectada según Censo 2005) } \\
\cline { 2 - 4 } & 285.713 & Urbana & Rural \\
\hline Armenia & 3.012 & 17.908 & 7.805 \\
\hline Buenavista & 74.846 & 57.378 & 1.779 \\
\hline Calarcá & 28.170 & 20.816 & 7.468 \\
\hline Circasia & 5.394 & 3.025 & 2.369 \\
\hline Córdoba & 13.070 & 6.729 & 6.341 \\
\hline Filandia & 9.063 & 4.587 & 4.476 \\
\hline Génova & 35.888 & 32.978 & 2.910 \\
\hline La Tebaida & 40.303 & 32.605 & 7.698 \\
\hline Montenegro & 6.513 & 3.785 & 2.728 \\
\hline Pijao & 34.345 & 27.950 & 6.395 \\
\hline Quimbaya & 7.215 & 3.693 & 3.522 \\
\hline Salento & 543.532 & 472.687 & 70.845 \\
\hline TOTAL & & & \\
\hline
\end{tabular}

Fuente: DANE (Tomada del plan de desarrollo vigente

\section{A $\quad \mathbf{N}$} Universidad Autónoma de Manizales 
A excepción del municipio de Buenavista en que el 60,3\% es población del área rural, los restantes 11 municipios del departamento tienen mayor concentración de su población en las cabeceras.

Armenia por su parte sola concentra el $52,5 \%$ de la totalidad de la población departamental, en tanto el $63,53 \%$ de la totalidad de la población reside en las áreas urbanas de Armenia y Calarcá.

El 11 \% de la población está entre 60 y más años de edad, expresión de la transición demográfica, y que significa el crecimiento de la proporción de la población de mayor edad, denominado envejecimiento poblacional, y a pesar de ser el departamento del Quindío, en el conjunto del Eje Cafetero, el de menor avance, o aún, de avance negativo en el Índice de Desarrollo Humano, la proporción en aumento - aunque lento- de la población envejeciente, genera efectos mayores sobre las tasas de dependencia, y una mayor vulnerabilidad para esta población (al igual que aquella población de la franja que todavía no está en edad de trabajar, o menor de 15 años), que vista en el contexto del desempleo crónico del departamento, situado sistemáticamente en los primeros lugares de este problema en el país, acentúa aún más su crisis social general, incluidas por supuesto las instituciones que por su razón, trabajan en pro de estas poblaciones.

\section{Infraestructura}

En cuanto a infraestructura y servicios públicos domiciliarios, en los informes preparatorios sobre el departamento del Quindío (CEIR UNI QUI NDí O), para el I nforme Regional de Desarrollo Humano del PNUD, que si han tenido variación, esta puede verse como una tendencia al mantenimiento y ampliación de las coberturas, aunque como se verá reflejado en el informe preparatorio, las diferencias más notables en calidad de servicios, en este caso los domiciliarios, se encuentra en la brecha urbano -rural. En dicho informe preparatorio se lee:

“En materia de infraestructura vial, el Quindío posee 1.37 kilómetros construidos por cada kilómetro cuadrado de área, uno de los índices de densidad vial más altos en Latinoamérica. A diferencia de otros departamentos, todas las vías de la red secundaria y parte de la red terciaria están pavimentadas, el $50.2 \%$ se encuentran en estado bueno, el $23.3 \%$ en estado regular y el $26.4 \%$ en estado malo; sobrepasa así los indicadores para el total nacional debido a que Colombia sólo tiene pavimentadas el $75 \%$ de sus vías, cuyo estado según la anterior clasificación corresponde al $72 \%, 20 \%$ y $8 \%$. Las vías no pavimentadas de Colombia representan el $25 \%$ y también se pueden clasificar por el estado en que se encuentran concluyendo que el $40 \%$ están buenas, el $38 \%$ regulares y el $21 \%$ malas $^{4}$.

Una dificultad derivada de este desarrollo infraestructural y que se está evidenciando actualmente, es que tanto su conservación así como con su ampliación futuras demandan una importante fracción de los recursos con que cuenta, lo cual distrae importantes fondos de sectores mas relacionados con el desarrollo socioeconómico, v. gr. salud, educación, saneamiento, etc.

En lo que respecta a servicios públicos domiciliarios, el departamento sobresale en el concierto nacional por la cobertura que presenta en energía eléctrica, acueducto, y telefonía. En esta última, en 1993 el Quindío contó con el 1.54\% de las líneas en el ámbito nacional, el $1.52 \%$ en 1997 y $1.42 \%$ para 1999 (reducción que se atribuye al

4 Bonilla, R. y Fonseca, C. Informe preparatorio

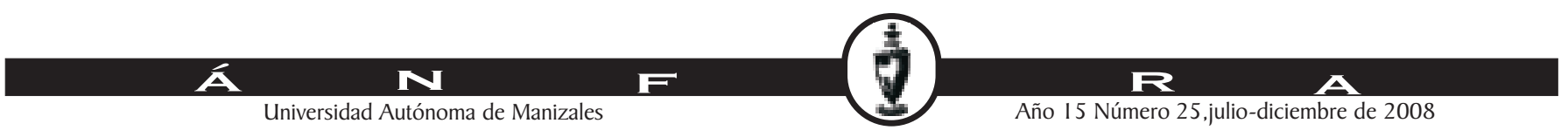


fenómeno natural que afectó la región ese año). Armenia con el $71 \%$ de los abonados del departamento se destaca en densidad telefónica con el $26.90 \%{ }^{5}$ frente al promedio nacional de $16.42 \%$, le siguen Calarcá con $13.92 \%$ y Circasia con $13.50 \%$. La densidad departamental promedio es de $10.5 \%$, lo que permite afirmar que falta un mayor cubrimiento de líneas telefónicas en los municipios pequeños y en el sector rural.

El servicio de energía presenta una altísima cobertura, cercana al 100\%, teniendo en cuenta que el Quindío no es generador de energía, por el contrario, el departamento compra energía para comercializar a su interior, esta es una de las debilidades de este servicio público, ya que presenta una dependencia eléctrica del resto del país y además existe una ausencia casi total de proyectos de generación eléctrica.

La cobertura de acueducto y alcantarillado antes del terremoto alcanzó en Armenia el $100 \%$ y en los municipios el $90.55 \%$ y el $80.10 \%$ respectivamente. Estos porcentajes superan la proporción nacional que fue de $89.65 \%$ y $78.90 \%$ de cobertura en capitales y de $88.75 \%$ y $74.72 \%$ en cabeceras de municipios. El índice de agua no contabilizada para Armenia fue del $36.35 \%$ que supera el promedio nacional que fue de $42.12 \%$ para el mismo año, es decir, a nivel nacional se tienen más pérdidas en comparación con el Quindío.

Sin embargo estos elevados índices ocultan serias deficiencias, como quiera que en las zonas rurales las coberturas son sensiblemente inferiores, por lo menos en alcantarillado no existen redes de conducción por tubería, los programas de saneamiento básico - de cobertura muy parcial y asociados mas al ordenamiento de las cuencas hidrográficas -, se han orientado al manejo de eliminación de excretas (pozos sépticos), sin un seguimiento mayor por parte de las administraciones locales. La calidad del agua, factor determinante de la calidad de vida, presenta grandes deficiencias en los municipios quindianos. Para el año 2000 el control bacteriológico adelantado por las autoridades sanitarias del departamento reportó que el $86 \%$ de los acueductos urbanos eran aceptables en tanto que en la zona rural solo el $17 \%$ tuvieron la misma calificación ${ }^{6}$. Por otro lado, en los municipios de Circasia, Quimbaya y Montenegro aun persisten fallas en las redes de distribución debido a los daños ocasionados por el terremoto de $1999^{7} . "$

\section{Una Introducción}

El reto es importante, no solo por las demandas de los objetivos por sí; sino y además porque ofrece la oportunidad de situar procesos frente a un grupo de indicadores, que suficientes en unos casos, e insuficientes en otros, dan la posibilidad de evaluar desde los planes desarrollo, documentos que generalmente declarativos y formales, de ley, y por requisito, rubrican unas intenciones hechas políticas, públicamente protocolizadas, y consensuadas con la representación legislativa del departamento - Asamblea- (y la nación expresado en el documento CONPES 091), y por lo tanto, que comprometen el buen nombre, como que son la expresión de consensos, y de actores, que debatiendo han llegado a acuerdos básicos, y cuya posibilidad de desdecirlos, sería simple y palmariamente, la deserción de los principios y falta a la fe pública, nada extraordinaria en el régimen clientelista, pero exigible en la perspectiva del control ciudadano e institucional.

\begin{tabular}{|l|}
\hline 5 Carta Estadística Quindío \\
2001.DAP, 2002 \\
6 Instituto Seccional de Salud \\
del Quindío -ISSQ-. Perfil \\
Epidemiológico 2000. Armenia, \\
Q.2001 \\
7 Indice De Desarrollo Humano \\
Departamento Del Quindio \\
Primera Parte: Informe \\
Diagnostico Y Contexto \\
Departamental Resultados IDH \\
\hline
\end{tabular}

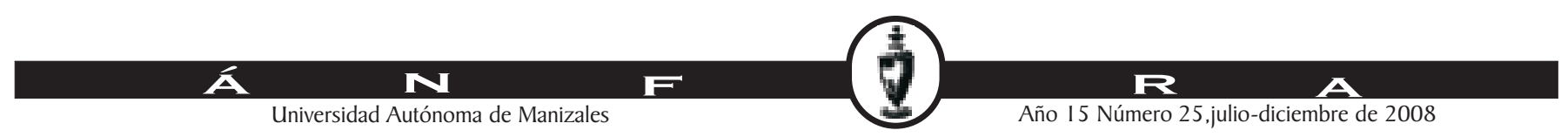


Los planes de desarrollo, en términos generales, sesudamente elaborados por contrato, terminan siendo en variados casos, hojas de ruta retóricas que justifican proyectos que secundariamente satisfacen sus propios objetivos, y tan solo para mantener con datos las obligaciones de ley, y así asegurados, poder trabajar con las agendas ocultas que los planes amparan.

Aquí, por el derecho que asiste a quienes han fijado la "hoja de ruta" para el siguiente cuatrienio, y el deber de los demás de acompañar observando desprejuiciadamente su desarrollo, presumimos la buena fe del plan y el compromiso transparente de sus administradores.

Como compromiso, la eficiencia que implica, y ella es posible bajo el principio de realidad de los diagnósticos, o tendencias sociales probables, y los recursos que demandan para apoyar procesos, o revertirlos por perversos frente a los principios de desarrollo y salud social, pero cuya eficacia puede estar comprometida por factores y fuerzas externas más o menos indomables, y que señalan un límite a la voluntad política.

Así, nos enfrentamos a dos sistemas si se quiere. El de la administración pública departamental y regional, y a los sistemas privados legales e ilegales como variables independientes, pero concurrentes; necesarias para evaluar en cada uno de los planos lo que le pertenece a cada una, según su lógica - intereses- y razón de ser social (laxa o controlada legalmente), para cuidar de adjudicar a una lo que es de otra.

Además, es un proceso dinámico de fuerzas, que se reconstruyen en los procesos de encuentro, y no solo puntos en planos cartesianos como si obedecieran a cotas prefijadas y neutras, en el que las metas de política son el horizonte porfiado.

Pero también, porque en el nivel de un Departamento, concurren distintas agencias de orden gubernamental pero descentralizadas, y de distintos niveles (nacional, regional, departamental) con sus propias agendas que no son fáciles para acompasar, de hacerlas coherentes, a pesar de las exigencias constitucionales, y entre estas, están las de los organismos de seguridad y las fuerzas militares, que deben obedecer al departamento y la localidad, pero se guían por los parámetros jerárquicos de cuerpo, entre otras lógicas y situaciones.

Entre otros, el caso evidente a los transeúntes y residentes, es el de las visibles incongruencias entre institutos de obra física: un día se rompe para acueducto y se repavimenta, para romper y repavimentar por gas, y romper y repavimentar por energía, haciendo las acometidas en el mismo espacio dispendiosas, costosas e irracionales, pero altamente justificadas por los planes de acción, inversión, y acceso a recursos de cada una de ellas.

Con esto señalamos falencias regulares significativas que ocurren en un orden todavía de resorte y autoridad local (incluida la departamental), cuando no, para agregarle más interferencia, siendo público el servicio, ha sido privatizado, y en casos, de agentes privados supralocales, es ya menor el margen de control aunque la ley les obligue.

El mundo más allá de ser un orden jurídico, se constituye en un juego de poderes que se sitúan diversamente frente a la ley, en un contexto de configuración estatal.

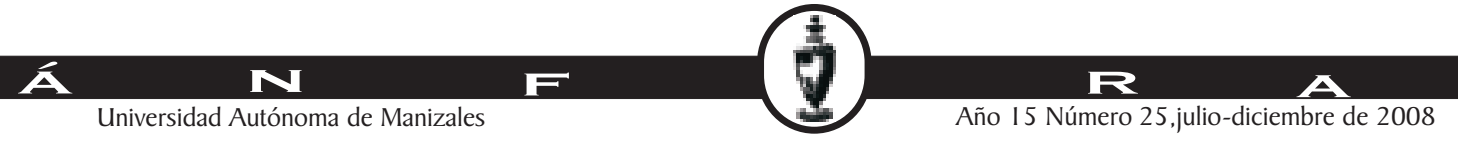


La desigualdad, la corrupción, la impunidad y la violencia son principios de realidad, y no discursos ofensores de la castidad señorial o puritana en una sociedad de las más desgarradas en el concierto internacional, y cuya actitud discreta, como criterio para evaluar la realidad socio - política señalaría la de la ingenua actitud del avestruz, o la muy grave, del ocultamiento.

\section{Consideraciones Básicas Mínimas para la contextualización de los ODM en el Departamento del Quindío}

La región, conocida como el Eje Cafetero, ampliada en la actualidad a la Ecoregión Cafetera, brindó, a través de su cultivo tradicional, el café, la primera fuente de divisas por varios lustros, y la estabilidad macroeconómica del país, y pasada la llamada violencia años 50, un ingreso seguro a sus poblaciones. La que ha sido su primera fuente económica, y su base para la estabilidad, con la apertura del mercado mundial tras la caída del pacto cafetero, se convertiría en su mayor incertidumbre.

El departamento del Quindío, el más pequeño del país, y con un producto interno bruto sustentado en el café, será el que más reciba el impacto de la crisis cafetera de un lado, y de la recesión económica de finales de los 90.

Ejemplar como parte del modelo de desarrollo agroexportador capitalista, con uno de los niveles de mayor infraestructura básica (vías primarias y secundarias, electricidad rural además de las cabeceras, acueductos urbanos y rurales, una red escolar amplia), producto de su mayoritaria vocación cafetera municipal, será prácticamente factura de la Federación de Cafeteros, y la que tomará las decisiones claves para la vida del departamento: la asistencia que brinda a los cultivadores, los situará bajo la dependencia de sus programas, y en subordinación tras la tecnificación, a través de la extensión de los servicios más típicamente urbanos como acueductos y electricidad al campo, que harán parte de los paquetes necesarios para la producción del grano en condiciones de competencia, y la que propiciará las modificaciones masivas del paisaje rural con los cambios de variedad en los cultivos, con la orientación preferente de la producción al mercado, abandonando definitivamente la economía campesina, o lo que quedaría de ella donde el modelo de aparcería se hacía dominante, y que arrastra de modo simultáneo, cambios en las redes sociales locales, y en la necesaria movilización de los productores al consumo comercial.

Este patrón de desarrollo, prohijado y promovido por la federación, sin duda resultó exitoso en sus cálculos, y en la redistribución de los beneficios a los (sus) cultivadores, en la parte primaria de la cadena del mercado mundial, donde afincó toda su potencia y hasta donde pudo sostenerse, amparada por el Pacto Internacional del Café, eslabón geoestratégico en la guerra fría.

Éxito que se debió también a una composición territorial que no exenta de conflictos agrarios en la colonización de la región, como los registra en su investigaciones Marco Palacios, terminaría por aclimatar un relativo status quo en la propiedad territorial, que desahoga la lucha por la tierra característica de otras regiones, y no por la leyenda rosa de una colonización democrática, que demuele Palacios, sino y entre otros factores, por la división geográfica de la tierra entre altas y de vertientes, y bajas y planas, confinando al campesinado a las laderas, pero liberado de las servidumbres de las atractivas tierras planas, sin que sea de manera total la homogeneidad en las unas y en las otras, que evidencia Absalón Machado (1988).

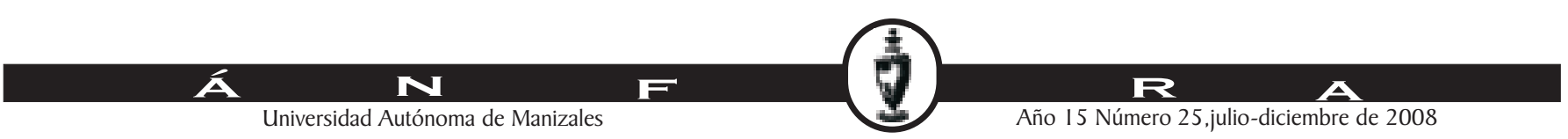


Así, el tono más democrático en la propiedad de la tierra, no es causa de una intención democratizadora a la base de la apropiación y distribución territorial; sino el efecto no contemplado de unas orientaciones y valoraciones sobre los usos del suelo, con consecuencias económicas, de los grandes colonizadores, y que hoy ya no pasan de ser valoraciones más simbólicas que efectivas, y por lo cual las tierras de la cordillera cambian de apreciación, para ser obj eto de mayor presión por nuevos inversionistas.

Cuando la reconstrucción post evento sísmico (año 1999), centralizada, planificada y jerarquizada desde el Fondo para la Reconstrucción del Eje Cafetero FOREC, cabeza de un conglomerado de organizaciones mayoritariamente particulares u ONGs, que suscitó un necesario debate por la función pública en manos de organizaciones privadas, como parte de una sorprendida reacción de los agentes locales, se soslaya, olvida o se reconoce poco, que para el departamento del Quindío en particular, gran parte de su historia como departamento había sido ya organizada y dirigida por la Organización particular no gubernamental de la Federación Nacional de Cafeteros, al lado de la cual la administración política y los políticos no llegaron a curtirse en los procesos de construcción social y planeación económica.

$\mathrm{Ni}$ para menospreciar ni sobreestimar, positiva o negativamente el papel de la Federación, se señala como un agente de primera línea, cuando no solitario en las dinámicas sociales del departamento, de las cuales la expresión económica fundamental de la existencia, ha sido marcada de manera decisiva en sus tendencias, por su planificada y sostenida intervención, lo que derivaría, a futuro y caído el pacto, en el talón de Aquiles del proceso, ahora por su retirada escalonada, efecto de las limitaciones severas que un mercado liberalizado provocaría.

Como se reiterará en este breve documento, con las evidencias aportadas por el Informe Regional de Desarrollo Humano 2004 “Un Pacto por la Región" del PNUD, en la perspectiva de los Objetivos de Desarrollo del Milenio, bajo unas condiciones particulares del desarrollo que este nuevo pacto entraña y modela para las naciones y regiones, las metas de los objetivos por supuesto que se articulan a procesos mucho más que mecánicos, y de pura planeación administrativa, técnica, financiera, que simplemente se operacionalizarían, incluidas unas notables oleadas de participación social y sectorial, para lograr más que menos, los estándares planteados.

Divulgación y participación que no solo podría ser leída como el envés de lo que se propone, y atribuida a un exceso de suspicacia, que podría en esa ruta, plantear la participación no como construcción de consensos sociales espontáneos posibilitados por las plataformas públicas para su expresión; sino la construcción de audiencias aprobatorias, habida cuenta de los principios que oferta, por la eficacia simbólica que entrañan y que solo por locura se estaría en desacuerdo con ellos: ¿quién negaría que la nutrición infantil, la disminución de la mortalidad maternoinfantil, la escolarización, etc, son deseables, derechos que ya el Iusnaturalismo hace siglos abrió para las siembras futuras de condiciones humanas, como inalienables, y que así, nacen con las personas?

Más que una lectura suspicaz, es el necesario criterio del principio de realidad sociológico, el que nos pone de cara a una historia en la que de modo fatal, es decir, de manera inevadible, se inscriben las políticas y pactos que entusiastas participaciones no revocan ni revierten, que hacen que los pactos, propuestas e ideales marchen por los márgenes de sus férreas tendencias y lógica, a menos que se constituyan en movimientos sociales a gran escala en lucha contra las condiciones imperantes.

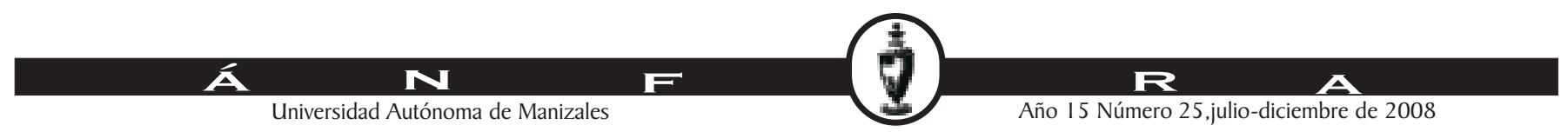


Es decir, se constituyan en fuerzas reales que pugnen no por alcanzar ciertos estándares, y no porque ellos no sean muy importantes; sino por la reformulación de la política, la economía y la cultura, para generar un desarrollo democrático sobre otras bases, para que sea democrático real, más que formal, una de cuyas consecuencias es el logro de estos y muchos otros estándares no cobijados en la propuesta concebida como la de una ética de mínimos, de los objetivos del milenio, para atraer a la multiplicidad de los gobiernos.

Tras el derrumbe parcial del Estado de Bienestar, modelo de modelos de la ola modernizadora, ej emplo del sí se puede desde el capitalismo racional, la misma Europa esplendente, cuna de la vía alterna, pasa hoy por inmensas afugias y crisis de paro y exclusiones críticas.

Si allí los problemas creciendo, parecen hacerse y se hacen inasibles por momentos para los sectores sociales y las administraciones públicas, aquí, la profundidad de las crisis, de los hábitos de apropiación y distribución, de las limitaciones administrativas, y de las alternativas de urgencia y de atajo para inmensos sectores poblacionales, multiplican las alertas que hacen necesario pisar sobre bases muy sólidas que trasciendan los buenos modales de la gobernabilidad a la que se deben por equidistancia las agencias oficiales, en primer lugar, con su tacto diplomático, las agencias de Naciones Unidas, y las agencias que a nombre de gobiernos y clientelas empresariales, por lo tanto, de potenciales inversores con ánimo de lucro, deben mantener, en una postura difícil, o audazmente conciliable entre la aquiesencia pro gubernativa y la movilización social reivindicativa.

En este, nuestro entorno y devenir, está fresco, menos en la memoria colectiva, que en los modos de acción, las estrategias de hacerse a posiciones y validarse en el tiempo de manera que se aparezca legítima la posición: grandes bienes de capital, como la tierra en el departamento del Quindío se adquirieron amparados y a la sombra de la violencia partidista, algunos de cuyos titulares son hoy prestigiosos hombres de negocios, y cuyas memorias judiciales están blindadas por un pasado local que se autoprotege en la urdimbre de muchos autores y dolientes que aspiran a no resucitar las sombras amenazantes del pasado.

Esto tiene un efecto sobre las posibilidades y limitaciones para la acción estratégica de las "corrientes inversionistas": en el lenguaje de los términos a la usanza aprestigiados, se trata que por esta razón, el departamento no tiene mucho que exhibir en cuanto a capital social moral, el de una ética que en principio opere como resistente contra la penetración de capitales siniestros, una oposición que más tarde o más pronto se puede encontrar inerme, pero que es en sí misma un principio de impugnación, un principio generador o generativo.

Con ello no se está planteando la ausencia de una ética del trabajo, o del yugo estoica y moralmente sobrellevado, pues basta levantarse como todos en la mañana para acompañarse de las corrientes laborales que tributan todos los días al mundo del trabajo, pero cuya capacidad de oposición por ahora está desarticulada en las estrategias de la sobrevivencia familiar (en la mayor proporción bajo el régimen de la informalidad); y quienes pueden hacerlo por sus acumulados, con las influencias convertibles de sus capitales en grupos de presión, siendo varios, no son al parecer la suficiente masa crítica para desatar el proceso por sí solos, que otras latitudes como en Bogotá, han podido hacerlo por su capital moral, de independencia de las masas

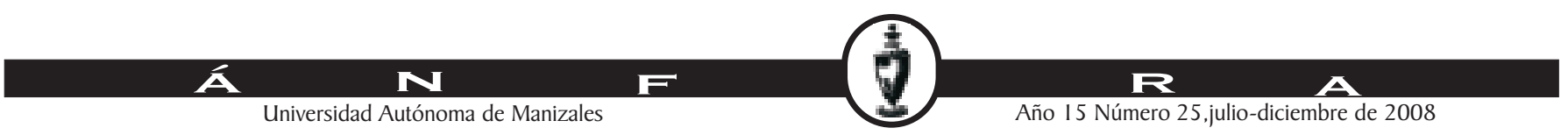


laborales y profesionalizadas al que un clientelismo entre oportunista y criminal no ha podido, por la racionalización creciente, en los términos de la misma modernidad, abarcar para sujetar.

No se dice que no es posible, sino todo lo contrario, que hay que hacerlo posible, implicando la evaluación de las condiciones y de ellas en su trayectoria histórica, que no es tampoco un dictamen cerrado, y si abierto a procesos creativos.

Lo viable y lo superable, para lo posible; y en la narcótica dicción, dar rienda suelta a nuestros sueños, pero ahora y con el poeta en mayúsculas, remontarse en las alturas es posible por la profundidad de las raíces: caracterizar una región es ir estableciendo el cuadro de fuerzas que la modelan, y en lo posible, de espacios "colonizables", desde donde se hace significativa la información demográfica, de empleo, de propiedad, y de movilidad de los factores.

\section{Plan de Desarrollo Departamental y ODM}

El Plan de Desarrollo Departamental 2008 - 2011, denominado "Quindío Unido", además de lo enunciado en la presentación, se asume como flexible e inacabado o abierto, posibilitando con ello, y de acuerdo a las dinámicas de la realidad, en sus horizontes local, departamental, regional, nacional e internacional, incorporar o redireccionar políticas y programas para el cumplimiento de las metas del Plan, entre las que están las del milenio:

“Nuestro compromiso se enmarca en la dinamización del desarrollo local y regional, interactuando en las tendencias de desarrollo nacional y global como un compromiso susceptible de ajuste y mejoramiento, según las condiciones determinantes en y para un mundo en permanente transformación y una población en transición".

Este criterio resulta importante y necesario para los momentos de puntualizar más las políticas, objetivos, programas y compromisos, en tanto los vacíos de información sobre metas desagregadas y línea de base; y el conocimiento creciente y de primera mano que arroja fungir como Estado en el subnivel nacional, de frente a realidades cuya intensidad solo era especulable, pero que permite ahora, con el saber de primera mano, de modo previsible, incorporar estas variables y factores, que de otra manera, impactarían sobre la política y sus rigideces en una colisión, al ser incuestionablemente hechos sociales de obligado curso de la realidad y su complejo devenir.

Sin otras posibilidades de verificación, consideramos como presunción de alto valor, este criterio que matiza el Plan de Desarrollo del Quindío.

Con este presupuesto de base y en consecuencia, luego de una pormenorizada lectura del Plan, anotar los vacíos frente a las ODMs, y de sesgo, los vacíos y retrocesos que algunos ODM entrañan.

El plan de desarrollo del departamento, en su exposición, se basa de modo reglamentario, en los preceptos fundamentales de la constitución de 1991 (autonomía, promoción del desarrollo, coordinación y complementariedad municipal, citando los principios de eficiencia y justicia social, y los criterios de objetividad, oportunidad y viabilidad); en el horizonte de la propuesta del mandatario (gestión pública por resultados), y como consecuencia de los aportes consensuados que surgieron en 23

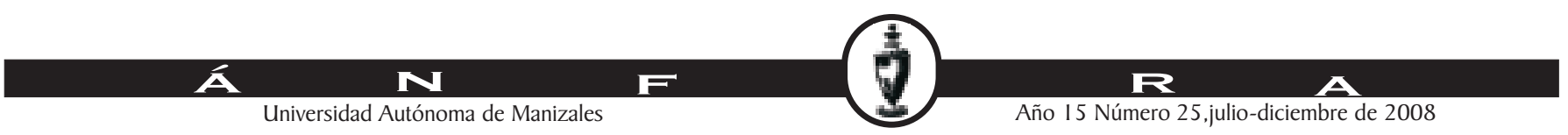


talleres y mesas temáticas con la participación de más de 1.300 personas, representando a las ONGs, los gremios, y lo que el documento denomina la "sociedad civil".

Pretende dinamizar el desarrollo local y regional según las condiciones del contexto nacional y mundial, desde una estrategia integral y democrática con buen uso y aprovechamiento de los recursos, para generar una mejor calidad de vida de los habitantes, bajo criterios internacionales de la buena gobernabilidad, de acuerdo a los criterios de la Comisión Económica para América Latina (CEPAL).

\subsection{La Estructura del Plan}

Se fundamenta en cuatro grandes políticas, planteadas en el texto como articuladas, que respondan a los cuatro componentes considerados básicos de la vida departamental: el territorial, el social, el económico y el gubernamental.

El Plan recoge como insumos ejercicios anteriores, construidos algunos en procesos de participación abierta, y sistemática intra - departamentales, como el Plan Estratégico Quindío 2020, los Planes de Ordenamiento Territorial, la Agenda Interna para la Productividad y la Competitividad, la Agenda de Ciencia y Tecnología; y los documentos nacionales: la Visión 2019 Segundo Centenario del gobierno nacional; y la agenda internacional oficial de Naciones Unidas conocida con el nombre de Los Objetivos de Desarrollo del Milenio.

Las fuentes variadas, pero también concurrentes, con que se ha concebido y planificado el desarrollo departamental, pretende superar la perspectiva denominada tradicional en la planificación, sin ceder en su concepción a agendas que de varias formas pueden resultar sustitutivas del proceso de construcción interno con su rico haz de ejercicios colectivos, al incorporar los objetivos del milenio como uno de los criterios básicos, entre otros criterios logrados.

Para el horizonte de la transversalidad necesaria en el proceso del conjunto departamental, la gobernación entrante ha conformado la Mesa de Planificación Departamental Quindío - Armenia - Municipios: “Pacto por la Integración y el Desarrollo del Quindío", y la CRCQ ${ }^{8}$.

Las políticas, de forma sintética, han sido presentadas textualmente como sigue:

- POLÍtICA TERRITORIAL Y AMBIENTAL “Quindío, un territorio integrado y competitivo", con la política territorial se pretende conocer el territorio en toda su dimensión física, desde su componente natural hasta la ordenación del mismo y sus entornos, utilizando todas las herramientas de planificación vigentes, que deben conducir al desarrollo de una infraestructura física que nos permita ser competitivos.

- POLÍTICA SOCIAL “Quindío con seguridad humana y compromiso social”, una vez concebido el territorio la población desarrolla sus actividades productivas y sociales, procurando su identidad y su bienestar. De esta forma se pretende desarrollar un sistema de seguridad social en salud, educación, seguridad alimentaria, cultura y deporte, ejecutando acciones a través de los programas: Quindío unido por la equidad social, sistema general de seguridad social en salud,
8 “...orientar el desarrollo armónico del departamento de forma articulada con todos los municipios,buscando la solución a problemas comunes aunando esfuerzos de manera concertada para lograr los objetivos propuestos, y armonizar los planes de desarrollo municipales con el Plan Departamental y los planes de ordenamiento territorial. Así mismo Bajo las directrices del $\mathrm{S}$ istema Nacional de Competitividad (SNC) se conformó mediante Decreto 351 de 10 de abril de 2008, la Comisión Regional de Competitividad del Quindío. (CRCQ), organismo articulador de las diferentes instancias y responsable del desarrollo departamental, es un espacio de concertación entre actores públicos, privados, academia y organizaciones cívicas y sociales; para orientar los esfuerzos hacia la consolidación d e un departamento competitivo".

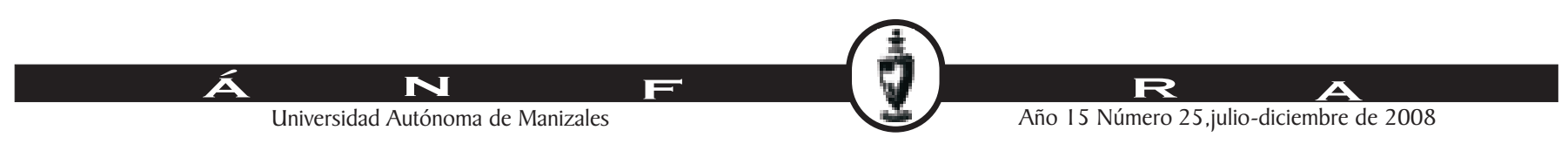


seguridad alimentaria y nutricional, sistema educativo articulado al sistema productivo, sistema departamental de cultura para la convivencia y la paz y sistema departamental del deporte, la recreación y educación física.

POLÍTICA ECONÓMICA “Quindío con desarrollo económico y tecnológico”, una vez concebido el territorio, sus actividades y relaciones sociales, se busca reactivar y diversificar los sistemas productivos, promoviendo la investigación científica, tecnológica y sus aplicaciones al sistema económico, para alcanzar la competitividad y sostenibilidad que le permita al departamento, aprovechar los tratados de libre comercio, para su proyección en los mercados globalizados. En este escenario se desea fortalecer la agroindustria, el turismo y las cadenas productivas promisorias esperando generar mayores niveles de productividad, empleo e ingreso.

POLÍTICA DE GOBERNABI LIDAD “Quindío una gerencia pública de impacto social”, uno de los componentes necesarios y modernizantes es la institucionalidad al servicio de los ciudadanos, aplicando los principios democráticos, participativos y transparentes. Aquí se concibe en términos integrados el territorio, la sociedad y sus actuaciones, sus relaciones y actividades económicas; todo lo cual requiere de una gobernabilidad pública y legitima, que permita trabajar con voluntad de servicio social, modernización en los procesos y procedimientos, utilizando la planeación estratégica para el desarrollo, una estrategia gerencial para la gobernabilidad, que generen sentido de pertenencia, cultura organizacional y confianza ciudadana en la institucionalidad y sus gobernantes. Combinando todos estos factores se aspira a gobernar generando un impacto social positivo, en bien de toda la ciudadanía quindiana.

\section{Misión del Plan}

Coordinar en consenso con las autoridades territoriales, la sociedad civil, los gremios, y la academia, todas las acciones encaminadas al logro de los objetivos y metas de este plan, complementar la acción de los municipios en la ejecución de sus planes estratégicos y de desarrollo, dentro del respeto de la autonomía local y lograr una intermediación entre los 12 municipios y la Nación en forma armoniosa y efectiva en todos los asuntos relacionados con la paz, el desarrollo y el bienestar de los ciudadanos.

\section{Visión del Plan}

El departamento del Quindio será en el 2011 un centro de desarrollo agroindustrial y turístico, posicionado en el mercado nacional y visible en el mercado internacional, generador de valor a través de encadenamientos productivos sostenibles, con calidad humana e identidad sustentada en la diversidad cultural.

\section{Objetivo Estratégico del Plan}

Integrar el territorio departamental como un ente competitivo, con calidad humana y compromiso social, con oportunidades de formarse técnica y científicamente y de desplegar sus capacidades en el desarrollo económico y social sostenible de la región y el mundo, a través de una moderna gerencia pública de consenso, confiabilidad y transparencia.

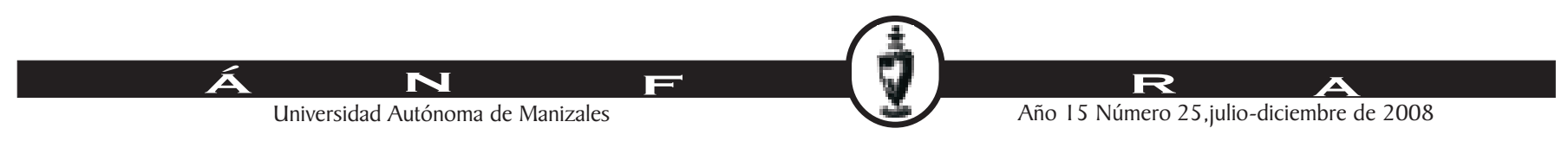




\subsection{Las Políticas por Objetivo y Meta}

\subsubsection{Política Territorial}

\section{Objetivo Territorial}

Definir lineamientos, promover la adopción de mecanismos para alcanzar el ordenamiento urbano y rural, la sostenibilidad y avanzar hacia la competitividad del departamento, en armonía con la región, el país y el mundo.

\section{Metas de Resultado Territoriales}

I mplementar el Sistema de Información Geográfico Departamental.

Integrar los 12 planes de ordenamiento territorial en un sistema de información.

Los objetivos y metas sectoriales de esta primera política están desagregados en tres programas con sus subprogramas y metas:

\section{Programa Patrimonio Natural}

\section{Objetivo Sectorial.}

Apoyar la articulación de los procesos de protección, recuperación y conservación ambiental, mediante estrategias de preservación y sostenibilidad de los recursos naturales y ejerciendo acciones para evitar el deterioro de los diferentes ecosistemas.

\section{Meta de Resultado Sectorial}

Subir tres puntos en la medición del escalafón del factor del medio ambiente. (Base el ranking de competitividad de los departamentos de Colombia. CEPAL 63.3 en 2000, 60.5 en 2004).

\section{Subprogramas: \\ Ecosistemas Estratégicos \\ Mecanismos de Protección Ambiental \\ Modelos Productivos Sostenibles}

\section{Programa Ordenación del Territorio.}

\section{Objetivo Sectorial.}

Implementar acciones que garanticen el cumplimiento de la normatividad vigente sobre el ordenamiento del territorio departamental, para alcanzar el desarrollo sostenible.

\section{Meta de Resultado Sectorial:}

Aumentar 4 puntos en la medición del escalafón del factor de infraestructura (Base el ranking de competitividad de los departamentos de Colombia. CEPAL 88.3 en 2000, 83.7 en 2004).

\section{Subprogramas:}

Instrumentos y Mecanismos del Ordenamiento Territorial

Sistema de Información Geográfico Departamental (SIGD)

Ciudades Amables y el Campo la Mejor Opción

Infraestructura para el Desarrollo Vial y Social

Vivienda de Interés Prioritario (VIP) y de Interés Social (VIS), Urbana y Rural

Gestión del Riesgo

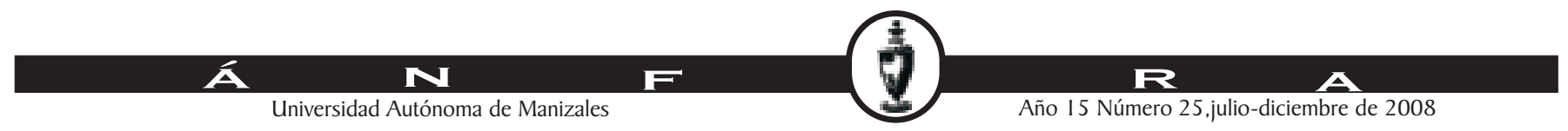




\section{Programa Entornos Territoriales para la Competitividad}

\section{Objetivo Sectorial}

Aprovechar en forma productiva el entorno territorial a través de la articulación, la integración y la dinamización de acciones que generen desarrollo económico local y competitividad de los sectores productivos del departamento.

\section{Meta de Resultado Sectorial.}

Apoyar la implementación de 12 planes de desarrollo económico y local acorde con la vocación y potencialidades de los municipios.

\section{Subprogramas \\ Plan Departamental de Aguas, Servicios Públicos y Saneamiento Básico Conectividad Quindío Digital \\ Proyectos Estratégicos \\ Gestión de Proyectos Estratégicos del Plan Nacional de Desarrollo \\ Gestión de Proyectos Estratégicos Regionales \\ Gestión de Proyectos Estratégicos Departamentales}

\subsubsection{Política Social}

\section{Objetivo Territorial}

Mejorar las condiciones de vida de la población quindiana propiciando una buena educación, tanto en cobertura, calidad, pertinencia y eficiencia; acceso a la salud, al deporte, la recreación y la cultura, a través de los programas presidenciales como Red J untos, Familias en Acción y otras estrategias de cooperación.

Metas de Resultado Territoriales

Aumentar el índice de desarrollo humano en un punto para el departamento del Quindío (PNUD-IDH, 2002,69\%).

Programa Quindío Unido, por la Equidad Social, en Desarrollo de los Objetivos del Milenio. Objetivo Sectorial.

\section{Objetivo Sectorial.}

Garantizar los derechos constitucionales, legales, los derechos humanos y el derecho internacional humanitario para el desarrollo integral de la infancia, la adolescencia, la juventud, el adulto mayor, equidad de género, la diversidad, las personas con discapacidad, las etnias, personas en situación de desplazamiento y desmovilizados, a través de las redes sociales.

\section{Metas de Resultado Sectorial}

Aumentar en 5 puntos la medición del escalafón del capital humano (Base el ranking de competitividad de los departamentos de Colombia. CEPAL, en 2000, 43, 3 - 2004 36,1).
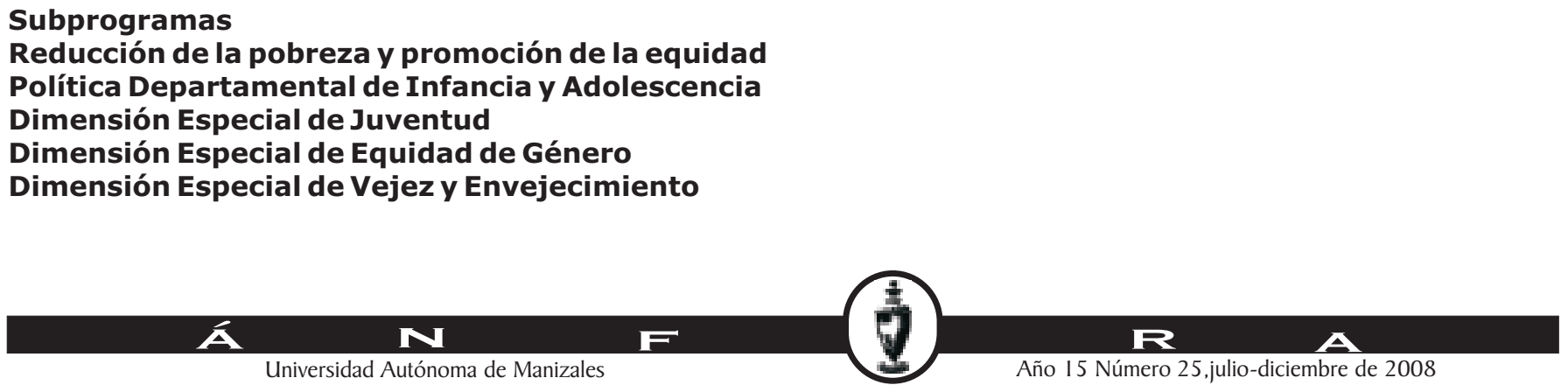
Dimensión Especial de Discapacidad

Dimensión Especial Puriétnica y Multicultural

Democracia Participativa

Dimensión Especial de Convivencia y Seguridad Ciudadana

Dimensión Especial en Derechos Humanos y Derecho Internacional

Humanitario

Prevención y Atención a la Población en Situación de Desplazamiento Forzado

Programa Sistema General de Seguridad Social en Salud.

Objetivo Sectorial.

Mejorar el estado actual de salud de la población quindiana mediante la articulación del sistema general de seguridad social y los procesos necesarios de inspección vigilancia y control del sistema de salud, para alcanzar una vida digna y saludable.

Meta de Resultado Sectorial

Promover la afiliación al 100\% de la población del departamento al Sistema

General de Seguridad Social en Salud (SGSSS).

Subprogramas:

Aseguramiento

Prestación y Desarrollo de Servicios de Salud

Salud Pública

Promoción Social en Salud

Prevención, Vigilancia y Control de Riesgos Profesionales

Emergencias y Desastres

Programa Seguridad Alimentaría Y Nutricional.

\section{Objetivo Sectorial}

Garantizar las condiciones necesarias de seguridad alimentaria y nutricional de manera progresiva, estable y sostenible a la población del Quindío de más alta vulnerabilidad, integrando acciones multisectoriales que permitan impactar positivamente su estado de nutrición y salud.

Meta de Resultado Sectorial

Disminuir los índices de desnutrición aguda, en población menor de 5 años de $12.3 \%$ al $10 \%$.

Disminuir los índices de desnutrición crónica, en población menor de 5 años de $26.2 \%$ al $25 \%$.

Apoyar con programas de seguridad nutricional a 199.239 personas, incluidas en el nivel uno del SISBEN del departamento.

\section{Subprogramas}

Producción y Suministro de Alimentos Sanos, Variados e Inocuos

Adquisición de Alimentos Nutritivos, Seguros e Inocuos de Manera Sostenible Consumo, Promoción de Hábitos y Estilos de Vida Saludables

Mejor Infraestructura Ambiental, de Servicios Públicos y Acceso a los

Servicios de Salud

Alimentos Seguros e Inocuos para toda la Población

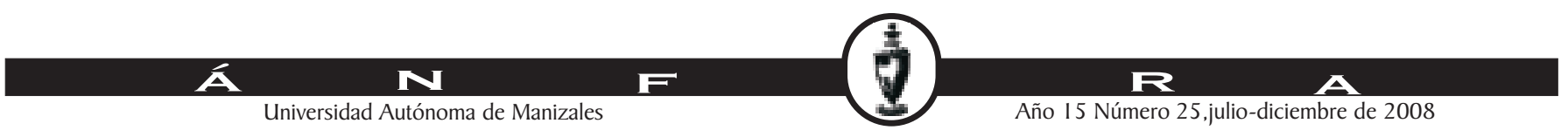


Programa Sistema Educativo Articulado al Sistema Productivo.

Objetivo Sectorial.

Articular el sistema educativo con el sistema productivo, para lograr el desarrollo integral de los usuarios del sector, mediante la oferta de una educación incluyente y relevante con cobertura, calidad y eficiencia.

\section{Meta de Resultado Sectorial}

Un sistema educativo articulado al sistema productivo, con cobertura, calidad y eficiencia. Desarrollar una estrategia para la masificación del aprendizaje de una segunda lengua en las instituciones educativas y las tecnologías de información y comunicación.

\section{Subprogramas \\ Garantizar el Acceso al Sistema Educativo Fomentar la Permanencia en el Sector Educativo \\ Alfabetización \\ Dotación y Mantenimiento de las Instituciones Educativas \\ Implementación de Especialidades y Modelos Educativos Flexibles \\ Incluir la Educación de la Primera Infancia \\ Educación Inclusiva con Calidad y Pertinencia \\ Modernización y Fortalecimiento de la Gestión de la Secretaría de \\ Educación \\ Sistema Educativo con Énfasis en la Formación para el Trabajo \\ Pertinencia de la Educación Técnica y Superior con el Desarrollo del \\ Departamento}

Programa Sistema Departamental de Cultura para la Convivencia y la Paz.

\section{Objetivo Sectorial.}

Consolidar el sistema departamental de Cultura, Integrado Por Las Instancias públicas y de participación ciudadana, de los municipios y el departamento dedicadas a la cultura, al igual que los esquemas de planificación, información y financiación; de modo tal que se articulen los procesos y se contribuya a la formación de una cultura de convivencia y paz en el Quindío.

\section{Meta de Resultado Sectorial}

Un Sistema Departamental de Cultura consolidado.

\section{Subprogramas}

Cultura con Dinámica Departamental y Nacional

Formación y Capacitación para el Fortalecimiento de los Procesos y

Servicios Culturales

Conservación y Preservación del Patrimonio Cultural

Cultura para la Convivencia y la Paz

Fortalecimiento del Fondo Mixto de la Cultura y las Artes

Programa Sistema Departamental del Deporte, la Recreación y la Educación Física.

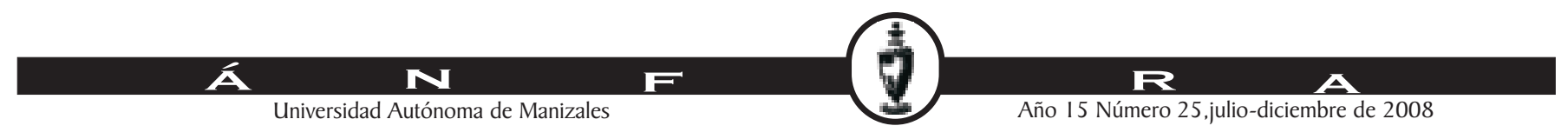




\section{Objetivo Sectorial.}

Mejorar el desarrollo sectorial desde los niveles competitivo, recreativo, de actividad física y aprovechamiento del tiempo libre, contribuyendo al fortalecimiento de estilos de vida saludable para la población quindiana.

\section{Meta de Resultado Sectorial}

Beneficiar 39.330 personas de los diferentes segmentos poblacionales del total de la población del Quindío participando en los programas de educación física, deporte y recreación.

\section{Subprogramas}

Educación Física, Estrategia para una Cultura Física

Deporte, Potencial para el Quindío.

Recreación

Eventos Deportivos

\section{Capacitación y Dotación Deportiva y Recreativa}

Sistema de Información

\subsubsection{Política Económica}

\section{Objetivo Territorial}

Reactivar y aumentar la productividad, mejorar la competitividad y la sostenibilidad de la economía quindiana, a través del fortalecimiento de la agroindustria y el turismo como modelo de desarrollo capaz de trascender y permitir al departamento posicionarse en el ámbito nacional e internacional.

\section{Meta de Resultado Territorial}

Aumentar cinco (5) puntos en la medición del escalafón del factor de fortaleza de la economía (Base el ranking de competitividad de los departamentos de Colombia. CEPAL en $2000=34.8$, en $2004=24.6$ ).

\section{Programa Reactivación Productiva}

\section{Objetivo Sectorial.}

I mplementar las acciones necesarias para el progreso del departamento, orientando y gestionando recursos de cofinanciación a todo nivel para reactivar, tecnificar y especializar el campo que logre un desarrollo productivo eficiente, que genere empleo y por consiguiente el bienestar para la población del departamento.

\section{Meta de Resultado Sectorial}

Disminuir la tasa de desempleo en el departamento del Quindío, en 2 puntos. $(2005=19.4$, DANE)

\section{Subprogramas}

Posicionamiento Nacional e Internacional

Desarrollo Económico para la Generación de Empleo

Política Integral Migratoria Departamental

\section{Programa Competitividad y Sostenibilidad}

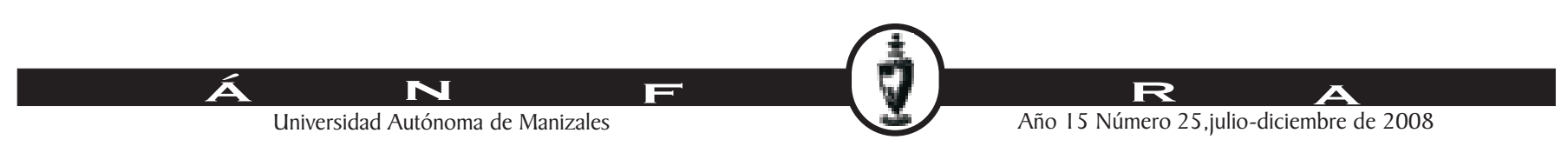




\section{Objetivo Sectorial.}

I mpulsar la especialización de servicios como el turismo y de la agroindustria en todo el territorio departamental, como potencialidades territoriales de gran impacto que marcaran la diferencia en los mercados.

\section{Meta de Resultado Sectorial}

Subir dos puntos en el factor de competitividad departamental, sosteniendo el rango alto. ( 2000 , puesto $8=43.9$ y en 2004 , puesto $9=40.2$ )

Mantener el Destino Quindío entre los tres primeros lugares en el ranking de competitividad turística que promueve el Ministerio de Comercio, Industria y Turismo a nivel nacional.

\section{Subprogramas \\ Plan Regional de Competitividad \\ Sistemas Productivos Promisorios Agropecuario, Forestal y Minero \\ Cadenas Productivas Agropecuarias \\ Cadenas de Servicios Especializados y Cluster de Turismo \\ Agroindustria Factor de Desarrollo \\ Emprendimiento y Empresarismo}

\section{Programa Investigación Científica y Tecnológica.}

\section{Objetivo Sectorial.}

Desarrollar procesos de investigación científica y tecnológica para que sean incorporados por los productores en sus procesos, permitiéndoles la especialización para diferenciar los productos del Departamento en los mercados nacionales e internacionales.

\section{Meta de Resultado Sectorial}

Aumentar tres puntos en la medición del escalafón del factor de ciencia y tecnología (Base el ranking de competitividad de los departamentos de Colombia CEPAL. En 2000, puesto $8=14.5$, en 2004 , puesto $11=17.1$ ).

\section{Subprogramas}

Agenda Departamental de Ciencia, Tecnología e Innovación Especialización y Diferenciación de Bienes y Servicios

\subsubsection{Política de Gobernabilidad}

\section{Objetivo Territorial}

Fortalecer la gobernabilidad e institucionalidad dentro y fuera de la administración, con la participación y el consenso ciudadano, a través de una gerencia pública orientada a resultados con altos rendimientos sociales.

\section{Meta De Resultado Territorial}

Cumplir con la ejecución total del Plan Departamental de Desarrollo 2008-2011.

\section{Programa Planeación Estratégica para el Desarrollo.}

\section{Objetivo Sectorial.}

Orientar, viabilizar, hacer seguimiento y evaluación a las políticas de desarrollo económico, social y ambiental del departamento, en coordinación de la administración
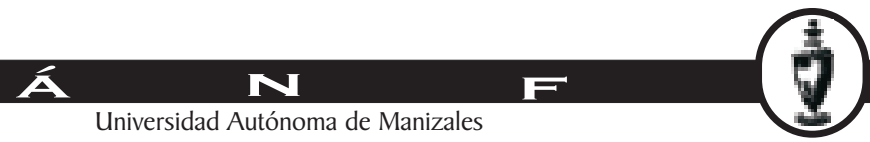
central con las municipales y los entes descentralizados de todo orden para lograr los objetivos propuestos en cada uno de los procesos de las políticas respectivas.

\section{Meta de Resultado Sectorial}

Determinar el modelo de desarrollo departamental y sus planes estratégicos que permitan implementarlo en todo el territorio.

\section{Subprogramas \\ Modelo y Visión del Desarrollo para el Departamento del Quindío}

\section{Programa Estrategia Gerencial para la Gobernabilidad.}

\section{Objetivo Sectorial.}

Aplicar estrategias gerenciales que nos permitan demostrar compromiso, agilidad, transparencia y efectividad en el manejo y gestión de los recursos para la inversión social, generando confianza ante la comunidad.

\section{Meta de Resultado Sectorial}

Evaluar anualmente la capacidad administrativa como unidades de gestión.

\section{Subprogramas \\ Organización y Modernización Administrativa y Financiera. Estrategia Comunicativa para la Región, Canal Telecafé.}

\subsubsection{Significado del Plan}

A lo largo del plan, a través de las cuatro políticas y sus desagregados, soportadas por los diagnósticos sectoriales y los estudios globales sobre Desarrollo Humano, se logra una visión de conjunto puesta en perspectiva, que, de lograrse, aclararía las rutas para unos óptimos en el desempeño social, desde las posibilidades de la política gubernamental subnacional.

Con esto, se afirma la necesariedad de la función administrativa, al tiempo que se prevé que su sola acción o combinada con espontáneas voluntades del empresariado, son insuficientes en los términos de unos desequilibrios sociales protuberantes, donde la desigualdad se inclina hacia los extremos de la acumulación y la pauperización.

El Informe del IDH del Eje Cafetero, avanzando algo en la lectura de la desigualdad, evidencia las diferencias departamentales entre capital y municipios, y entre áreas urbanas y rurales; pero es evidente que las diferencias se hacen críticas y desgarradoras entre sectores y clases sociales.

En términos del I nforme:

“El examen de las desigualdades - tanto en términos económicos como en relación con el desarrollo humano- debe considerar la ubicación geográfica de la población, dada su trascendencia en términos de las polaridades centro- periferia, urbano-rural. La alta concentración de la oferta de bienes y servicios en zonas específicas frena el crecimiento económico y el desarrollo humano, dado que tal concentración limita el

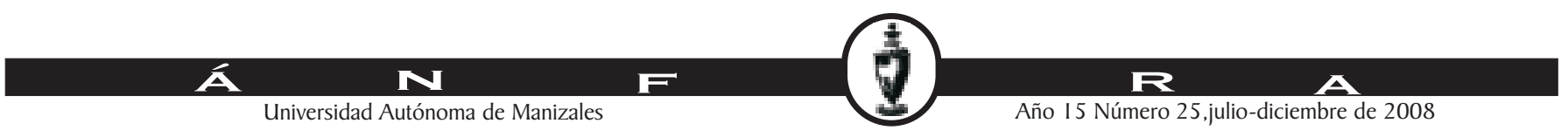


acceso a las oportunidades de ampliación de la capacidad humana y genera percepciones de desprotección, cuando no de discriminación".

(IRDH Un pacto por la región, PNUD, 2004)

El Plan Departamental avanza más allá de los lineamientos y supuestos del documento CONPES 091, en materia específica, sobre la reducción de la pobreza, al presentar un conjunto de programas para el fomento del capital humano, social y empresarial.

Sin embargo, y como es de esperarse, no puede avanzar mucho más allá del fomento y apoyo a empresas asociativas de una parte; a la formación para competencias educativas y laborales; a la evaluación sectorial regional para la articulación y pertenencia educativa y vocacional; y de otra, a la gestión y fomento de capacidad competitiva, que siendo necesarias, en tanto la órbita de su acción está limitada a amparar legalmente la política económica nacional, y a intervenir indirectamente a través de impuestos y recaudo en materias de ley, resultan insuficientes para afrontar con decisión, políticas redistributivas sobre el capital en un enfoque de equidad.

\subsection{Los Objetivos de Desarrollo del Milenio Dentro del Plan de Desarrollo}

Los ODMs están contemplados, como se ha leído, en la Política Social:

Política Social "Quindío, con seguridad humana y compromiso social"

En su parte expositiva, el documento señala para esta política, como sus derroteros:

"la promoción del cambio para un desarrollo humano, equitativo y sostenible, entendiendo el desarrollo humano como la creación permanente de las oportunidades para que los hombres, mujeres, niñas, niños, adolescentes y jóvenes puedan tener una vida larga y digna, acceso al conocimiento, bienestar y participación activa en los asuntos colectivos. Es importante entonces promover la formación de un individuo comprometido, participativo, con mentalidad abierta al cambio; así como lideres honestos que promuevan y aglutinen la comunidad alrededor de proyectos productivos de gran impacto social; estos elementos son fundamentales para construir una sociedad, dignificar el ser humano, buscar la equidad y la justicia, disminuir los conflictos, aumentar la seguridad, para entender que tenemos deberes y compromisos como ciudadanos. El derecho del pueblo a vivir libres del miedo y la necesidad, disfrutando de manera equitativa sus derechos y desarrollando a plenitud su potencial humano".

\section{Programa Quindío Unido, por la Equidad Social, en Desarrollo de los Objetivos del Milenio.}

\section{Objetivo Sectorial.}

Garantizar los derechos constitucionales, legales, los derechos humanos y el derecho internacional humanitario para el desarrollo integral de la infancia, la adolescencia, la juventud, el adulto mayor, equidad de género, la diversidad, las personas con discapacidad, las etnias, personas en situación de desplazamiento y desmovilizados, a través de las redes sociales. 


\section{Metas de Resultado Sectorial}

Aumentar en 5 puntos la medición del escalafón del capital humano (Base el ranking de competitividad de los departamentos de Colombia. CEPAL, en 2000, 43,3 - 2004 $36,1)$.

\section{Subprogramas}

Reducción de la pobreza y promoción de la equidad

En su parte declarativa, el Plan aclara que: "El logro de sus Objetivos están inmersos en las diferentes políticas, programas y subprogramas del Plan de Desarrollo, de acuerdo a las temáticas pertinentes"; sin embargo, como meta específica, plantea la misma del orden nacional:

Para cada programa y subprograma se plantean metas, unas de cubrimiento que parten de 0 para alcanzar determinada población, y otras, con reducción de índices o su aumento, según las cifras de las agencias.

\begin{tabular}{|l|c|c|}
\hline \multicolumn{2}{|c|}{ PRINCIPALES METAS } & \multicolumn{2}{c|}{ INDICADOR } \\
\cline { 2 - 3 } & BASE & ESPERADO \\
\hline $\begin{array}{l}\text { Acompañar a los municipios en la implementación de la } \\
\text { estrategia nacional Red Juntos que beneficiará a } 30.000 \\
\text { tamilias Sisben nivel 1 y desplazados. }\end{array}$ & 0 & 30,000 \\
\hline
\end{tabular}

A continuación resaltaremos, de acuerdo a los ODMs y los compromisos nacionales, los objetivos que aparecen con metas y línea de base.

En la medida en que, como lo anota el mismo plan, la asignación presupuestal está dispersa en el mismo, extractando del plan de inversiones, se presentan los cuadros presupuestales por programa en vez de por objetivo y meta del milenio.

Es necesario tener en la cuenta que además, los objetivos departamentales son el resultado de los agregados municipales, que se suman, en programas e inversiones, a los presupuestos del departamento para el resultado final.

El municipio de Calarcá, además cuenta, como piloto de la agencia GTZ, y Paipa en Boyacá, cada uno, con un plan específico para el desarrollo de los objetivos del milenio. 


\begin{tabular}{|c|c|c|c|c|c|c|c|c|}
\hline \multirow{3}{*}{\multicolumn{2}{|c|}{$\begin{array}{l}\text { ESTRUCTURA DEL PLAN DE } \\
\text { DESARROLLO 2008-2011 } \\
\text { “QUINDÍO UNIDO” }\end{array}$}} & \multirow{2}{*}{\multicolumn{6}{|c|}{$\begin{array}{l}\text { FUENTES DE FINANCIACIÓN DEL DEPARTAMENTO PRECISANDO SU } \\
\text { DESTINACIÓN 2008-2011 }\end{array}$}} & \multirow[t]{4}{*}{ TOTAL 2008-2011 } \\
\hline & & & & & & & & \\
\hline & & ORDINARIO & \multicolumn{2}{|c|}{ ESPECÍFICO } & SGP & CRÉDITO & GESTIÓN & \\
\hline PROGRAMA & \multicolumn{2}{|l|}{ SUBPROGRAMA } & & Fuente & & & & \\
\hline $\begin{array}{l}\text { 2,1. Quindío } \\
\text { unido por la } \\
\text { equidad } \\
\text { social }\end{array}$ & $\begin{array}{l}\text { 2, 1,1 Objetivos de } \\
\text { desarrollo del } \\
\text { milenio en nuestro } \\
\text { departamento. }\end{array}$ & 384.000 .000 & 0 & & 0 & 0 & 0 & 384.000 .000 \\
\hline & $\begin{array}{l}\text { 2, 1,2 Política } \\
\text { departamental de } \\
\text { infancia y } \\
\text { adolescencia. }\end{array}$ & 200.000 .000 & 0 & & 0 & 0 & 0 & 200.000 .000 \\
\hline & $\begin{array}{l}\text { 2,1,3 Política } \\
\text { Departamental de } \\
\text { juventud. }\end{array}$ & 130.000 .000 & 0 & & 0 & 0 & 0 & 130.000 .000 \\
\hline & $\begin{array}{l}\text { 2,1,4 Política } \\
\text { Departamental de } \\
\text { equidad de género. }\end{array}$ & 100.000 .000 & 0 & & 0 & 0 & 0 & 100.000 .000 \\
\hline & $\begin{array}{l}\text { 2, 1,5 Política de } \\
\text { vejez y } \\
\text { envejecimiento. }\end{array}$ & 120.000 .000 & 0 & & 0 & 0 & 0 & 120.000 .000 \\
\hline & $\begin{array}{l}\text { 2, 1,6 Política } \\
\text { departamental de } \\
\text { discapacidad. }\end{array}$ & 100.000 .000 & 0 & & 0 & 0 & 0 & 100.000 .000 \\
\hline & $\begin{array}{l}\text { 2, 1,7 Política } \\
\text { pública pluriétnica } \\
\text { y multicultural. }\end{array}$ & 80.000 .000 & 0 & & 0 & 0 & 0 & 80.000 .000 \\
\hline & $\begin{array}{l}\text { 2, 1,8 Democracia } \\
\text { participativa. }\end{array}$ & 120.000 .000 & 0 & & 0 & 0 & 0 & 120.000 .000 \\
\hline & $\begin{array}{l}\text { 2, 1,9 Política } \\
\text { departamental de } \\
\text { convivencia y } \\
\text { seguridad } \\
\text { ciudadana. }\end{array}$ & 10.000 .000 & & FS O & 0 & $\begin{array}{l}7.000 .000 . \\
000\end{array}$ & 0 & 7.010 .000 .000 \\
\hline & & 0 & & FS P & 0 & 0 & 0 & 0 \\
\hline & & & 233.901 .779 & & & & & 233.901 .797 \\
\hline & $\begin{array}{l}\text { 2, 1,10 Política } \\
\text { departamental en } \\
\text { derechos humanos } \\
\text { y DIH. }\end{array}$ & 70.000 .000 & 0 & & 0 & 0 & 0 & 70.000 .000 \\
\hline & $\begin{array}{l}\text { 2, 1,11 Prevención } \\
\text { y atención en } \\
\text { situación de } \\
\text { desplazamiento } \\
\text { forzado. }\end{array}$ & 70.000 .000 & 0 & & 0 & 0 & 0 & 70.000 .000 \\
\hline
\end{tabular}




\begin{tabular}{|c|c|c|c|c|c|c|c|c|}
\hline \multirow[t]{9}{*}{$\begin{array}{l}2,2 \text { Sistema } \\
\text { general de } \\
\text { seguridad } \\
\text { social en } \\
\text { salud } \\
\end{array}$} & $\begin{array}{l}2,2,1 \\
\text { Aseguramiento. }\end{array}$ & 0 & 1.685 .721 .952 & $\mathrm{RC}$ & 0 & 0 & 0 & 1.685 .721 .952 \\
\hline & & 0 & 318.484 .800 & MONO & 0 & 0 & 0 & 318.484 .800 \\
\hline & $\begin{array}{l}\text { 2, 2,2 Prestación y } \\
\text { desarrollo de } \\
\text { servicios de salud. }\end{array}$ & 0 & & RC & $\begin{array}{l}52.322 .581 \\
843\end{array}$ & 0 & 0 & 52.322 .581 .843 \\
\hline & & 0 & & RC OP & 0 & 0 & 0 & 0 \\
\hline & & 0 & & MONO & 0 & 0 & 0 & 0 \\
\hline & $\begin{array}{l}\text { 2, 2,3 Salud } \\
\text { pública. }\end{array}$ & 0 & 1.671 .204 .016 & & 7.880.234.832 & 0 & 0 & 9.551 .438 .848 \\
\hline & $\begin{array}{l}\text { 2, 2,4 Promoción } \\
\text { social en salud. }\end{array}$ & 0 & 80.000 .000 & & 0 & 0 & 0 & 80.000 .000 \\
\hline & $\begin{array}{l}2,2,5 \text { Vigilancia y } \\
\text { control de riesgos } \\
\text { profesionales. }\end{array}$ & 0 & 80.000 .000 & & 0 & 0 & 0 & 80.000 .000 \\
\hline & $\begin{array}{l}\text { 2, 2,6 Emergencias } \\
\text { y desastres en } \\
\text { salud. }\end{array}$ & 0 & 80.000 .000 & & 0 & 0 & 0 & 80.000 .000 \\
\hline \multirow[t]{5}{*}{$\begin{array}{l}2,3 . \\
\text { Seguridad } \\
\text { alimentaria } \\
\text { y nutricional }\end{array}$} & $\begin{array}{l}\text { 2, 3,1 Producción y } \\
\text { suministro de } \\
\text { alimentos sanos, } \\
\text { variados e inocuos. }\end{array}$ & 0 & & & 0 & 0 & 0 & 0 \\
\hline & $\begin{array}{l}\text { 2, 3,2 Adquisición } \\
\text { de } 130.000 .000 \\
\text { alimentos } \\
\text { nutritivos, seguros } \\
\text { e inocuos de } \\
\text { manera sostenible. }\end{array}$ & 130.000 .000 & 0 & MONO & 0 & 0 & 0 & 130.000 .000 \\
\hline & $\begin{array}{l}\text { 2, 3,3 Consumo, } \\
\text { promoción hábitos } \\
\text { y estilos de vida } \\
\text { saludables. }\end{array}$ & 70.000 .000 & 0 & & 0 & 0 & 0 & 70.000 .000 \\
\hline & $\begin{array}{l}\text { 2, 3,4 Mejor } \\
\text { infraestructura } \\
\text { ambiental, de } \\
\text { servicios públicos y } \\
\text { acceso a los } \\
\text { servicios de salud. }\end{array}$ & 60.000 .000 & 0 & & 0 & 0 & 0 & 60.000 .000 \\
\hline & $\begin{array}{l}\text { 2, 3,5 Alimentos } \\
\text { seguros e inocuos } \\
\text { para toda la } \\
\text { población. }\end{array}$ & 60.000 .000 & 0 & & 0 & 0 & 0 & 60.000 .000 \\
\hline
\end{tabular}

\section{A N}




\begin{tabular}{|c|c|c|c|c|c|c|c|c|}
\hline $\begin{array}{l}\text { 2, 4. Sistema } \\
\text { educativo } \\
\text { articulado al } \\
\text { sistema } \\
\text { productivo }\end{array}$ & $\begin{array}{l}\text { 2, 4,1 Garantizar el } \\
\text { acceso al sistema } \\
\text { educativo. }\end{array}$ & 768.000 .000 & 2.164 .719 .000 & MONO & 0 & 0 & 0 & 2.932.719.000 \\
\hline & & & 548.894 .514 & RB & & & & 548.894 .514 \\
\hline & $\begin{array}{l}\text { 2, 4,2 Fomentar la } \\
\text { permanencia en el } \\
\text { sector educativo. }\end{array}$ & 0 & 27.000 .000 & MONO & 0 & 0 & 0 & 27.000 .000 \\
\hline & $\begin{array}{l}2,4,3 \\
\text { Alfabetización. }\end{array}$ & 0 & 40.000 .000 & MONO & 0 & 0 & 0 & 40.000 .000 \\
\hline & $\begin{array}{l}\text { 2, 4,4 Dotación y } \\
\text { mantenimiento de } \\
\text { las instituciones } \\
\text { educativas. }\end{array}$ & 0 & 395.000 .000 & MONO & 0 & 0 & 0 & 395.000 .000 \\
\hline & & & 293.000 .000 & RB & & & & 293.000 .000 \\
\hline & $\begin{array}{l}2,4,5 \\
\text { Implementación de } \\
\text { especialidades y } \\
\text { modelos educativos } \\
\text { flexibles. }\end{array}$ & 0 & 425.000 .000 & MONO & 0 & 0 & 0 & 425.000 .000 \\
\hline & $\begin{array}{l}\text { 2, 4,6 Incluir la } \\
\text { educación de la } \\
\text { primera infancia. }\end{array}$ & 0 & 302.000 .000 & MONO & 0 & 0 & 0 & 302.000 .000 \\
\hline & $\begin{array}{l}\text { 2, 4,7 Educación } \\
\text { inclusiva con } \\
\text { calidad y } \\
\text { pertinencia. }\end{array}$ & 0 & 1.058 .608 .159 & MONO & 0 & 0 & 0 & 1.058 .608 .159 \\
\hline & & & 69.867 .136 & RB & & & & 69.867 .136 \\
\hline & $\begin{array}{l}2,4,8 \\
\text { Modernización y } \\
\text { fortalecimiento de } \\
\text { la gestión de la } \\
\text { secretaria de } \\
\text { educación. }\end{array}$ & 0 & 375.505 .020 & MONO & 0 & 0 & 0 & 375.505 .020 \\
\hline & $\begin{array}{l}\text { 2, 4,9 Sistema } \\
\text { educativo con } \\
\text { énfasis en la } \\
\text { formación para el } \\
\text { trabajo. }\end{array}$ & 0 & 1.407 .637 .811 & MONO & 0 & 0 & 0 & 1.407 .637 .811 \\
\hline & $\begin{array}{l}\text { 2, 4,10 Pertinencia } \\
\text { de la educación } \\
\text { técnica y superior } \\
\text { con el desarrollo del } \\
\text { departamento. }\end{array}$ & 0 & 2.441 .600 .002 & MONO & 0 & 0 & 0 & 2.441 .600 .002 \\
\hline
\end{tabular}




\begin{tabular}{|c|c|c|c|c|c|c|c|c|c|c|}
\hline & INDICADOR & LINEA BASE & AÑO & FUENTE & META & $\begin{array}{l}\text { Explicita } \\
\text { PDD }\end{array}$ & $\begin{array}{l}\text { Implícita } \\
\text { PDD }\end{array}$ & NO CONTEMPLADA & $\begin{array}{l}\text { INVERSIÓN } \\
\text { POAI }\end{array}$ & \begin{tabular}{|ll} 
Meta & $/$ \\
ODM & a \\
2015 & - \\
Colombia &
\end{tabular} \\
\hline \multirow{6}{*}{$\begin{array}{l}\text { ODM: } \quad 1 \\
\text { Erradicar la } \\
\text { pobreza y } \\
\text { el hambre }\end{array}$} & $\begin{array}{l}\text { 1. Línea de } \\
\text { Pobreza }\end{array}$ & $45.63 \%$ & 2005 & DNP & & & & PDD & & $28 \%$ \\
\hline & $\begin{array}{l}\text { 2. Línea de } \\
\text { indigencia }\end{array}$ & $11.80 \%$ & 2005 & DNP & & & & PDD & & $9 \%$ \\
\hline & $\begin{array}{l}\text { 3. Desnutrición } \\
\text { global }\end{array}$ & & & & & & & PDD & & $3 \%$ \\
\hline & $\begin{array}{l}\text { 4. Desnutrición } \\
\text { Aguda } \\
\text { menores de } 5 \\
\text { años }\end{array}$ & $12.3 \%$ & 2008 & PDD & $10 \%$ & $\mathrm{x}$ & & & & \\
\hline & $\begin{array}{l}\text { 5. Desnutrición } \\
\text { crónica } \\
\text { menores de } 5 \\
\text { años }\end{array}$ & $26.2 \%$ & 2008 & PDD & $25 \%$ & $\mathrm{x}$ & & & & \\
\hline & 6. NBI & $16.04 \%$ & 2005 & DNP & & & & & & \\
\hline
\end{tabular}

DNP: Departamento Nacional de Planeación. PDD: Plan de Desarrollo Departamental 2008-2011.

Los indicadores son los acordados por Colombia.

En el Plan Plurianual de Inversiones, para los Objetivos de Desarrollo del Milenio se tiene contemplada una inversión de 384 millones global, no desagregada; pero en rubro aparte, para la política departamental de infancia y adolescencia, 200 millones, para equidad de género 200 millones.

Como se observa, en el Plan de Desarrollo Departamental (PDD), para el Objetivo ODM 1 , el grueso del conjunto de metas del objetivo no aparecen especificadas, o bien, como en el caso de la desnutrición, aparece no la global, sino desagregada.

En pobreza, el mismo PDD, consigna que: “Un 92\%, de la población del departamento se ubica en los niveles 1, 2 y 3 del SISBEN. Grupo que se encuentran (sic) en situación de vulnerabilidad, mas critico es que las mayores tasas de desempleo y las menores de ocupación están en los niveles 1 y 2 , con lo cual se agravan las condiciones de pobreza y miseria"( pág. 46 dcto electrónico).

El PIB, expresión de la dinámica económica departamental, como bien se ha establecido en el Informe Regional de Desarrollo Humano, ha representado un retroceso, más que un relativo estancamiento como lo afirma el PDD. Del mismo plan, en cifras comparativas con el PIB nacional, presenta el siguiente cuadro:

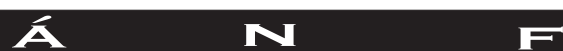

Universidad Autónoma de Manizales 


\section{Porcentaje del PIB Departamentalen el PIB Nacional}

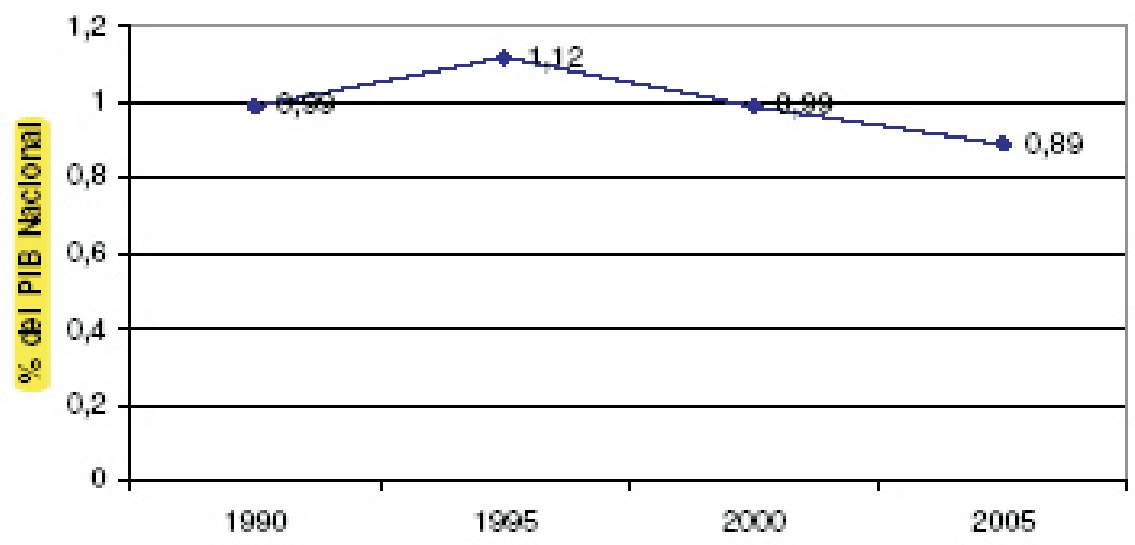

Fuente: Dane-SEDRA

El cuadro siguiente presenta una visión de 55 años que va desde 1950 a 2005. Presentan diferencias leves, y una más marcada en el año 1995, con todo, manifiestan la misma dinámica descendente del PIB departamental.

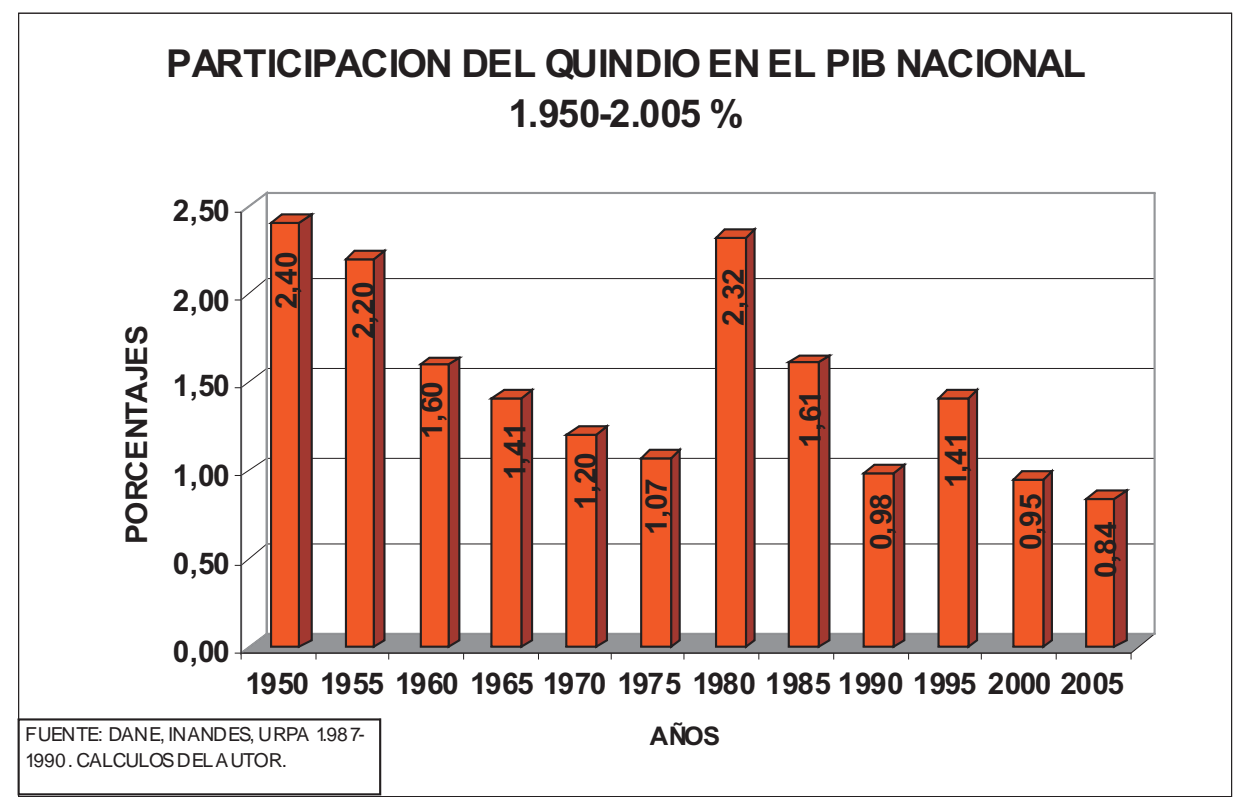

Fuente: Contexto socioeconómico y el gasto público en educación y su transferencia a los municipios del departamento del Quindío y Armenia. Septiembre de 2008. (Fondo para la Acción Ambiental y la Niñez, Colombia; The coffee people; Fundación Luis Felipe Vélez, Save the Children - Reino Unido. Consultor: Mario Alberto Álvarez Marín.)

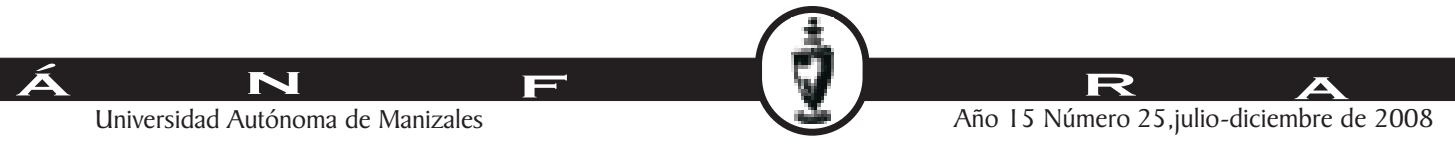


El concepto de pobreza ha tenido que variar en el tiempo, desplazándose desde el desarrollo económico al de desarrollo humano, y en la lógica del anterior, derivar hacia el de seguridad humana, respecto del cual se dan las versiones desde una exigente y radical, que pone el acento en un horizonte no aleatorio, a otra de carácter mínimo, que pone el acento en las franjas denominadas vulnerables de la población.

Sin embargo, como ya se ha observado, para los Objetivos, se regresa, desagregando, a los indicadores de pobreza y miseria, como cuantificables para su seguimiento, por sobre el combinado del IDH.

La caída del Pacto Cafetero y la consecuente volatilidad de los precios en el mercado; la recesión económica nacional hacia finales de los 90 combinada con los bajos precios del café; el terremoto de 1999 con marcada afectación para el Quindío y una transitoria inversión de magnitud para su reconstrucción (principalmente área física, con un estimado de $2 \%$ en inversión social sin infraestructura, que destaca el CEIR U.Q. "La Reconstrucción del Quindío. Lecturas desde la Academia, Universidad del Quindío, Armenia 2004"); y la violencia común u organizada, son los factores que marcan con fuerza el desarrollo humano en la región, como lo consigna el I nforme regional PNUD 2004.

El más afectado en el conjunto regional, en su desarrollo humano, viene siendo el departamento del Quindío.

Recordemos que el Desarrollo Humano es el índice combinado de PIB per cápita, índice de logro educativo, y esperanza de vida al nacer.

Con las limitaciones que el IDH pueda tener, es más expresivo en develar la relación necesaria y fundamental que la salud y acceso a los demás derechos - capacidades tienen con la producción económica y los ingresos de las personas y familias, para generar un marco de oportunidades más reales de desarrollo, que en las metas acordadas por Colombia se resuelven con redistribución bajo la forma de servicios de salud y educación, básicos, pero previos y como constelación hacia el objetivo de ingresos y la independencia.

Y será, en esta relación directa, que el departamento, además del desarrollo desigual entre sus clases sociales, en su dinámica económica presenta la más incierta y baja posibilidad de crecimiento.

En artículo de El Tiempo, del 19 de abril de 2007, se señala que, "los logros (de los ODM) se ven opacados por la mala distribución del ingreso, según el informe Global Monitor Report 2007, del Banco Mundial... En Colombia, la tasa de mortalidad de niños menores de cinco años asciende a 39,1 por cada mil entre los más pobres y a 15,1 por cada mil entre los más pudientes, lo que constituye, según el Banco, una prueba de que la desigualdad de ingresos influye en la mortalidad en la niñez".

En el mismo artículo, de Laura Charry de la redacción económica, reseña a J airo Núñez, director de la Estrategia para la Reducción de la Pobreza y la Desigualdad, que "explica que en los últimos cuatro años la mala distribución del ingreso no se redujo en la misma proporción que la pobreza y que esto se debe a que la desigualdad es un problema muy difícil de solucionar, dado que se requiere redistribuir la tierra, la educación y los subsidios. "Y eso se logrará mucho después del 2015", que es la fecha en la que se deben cumplir las Metas del Milenio".

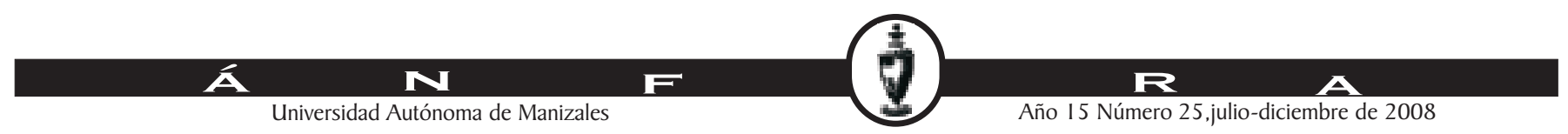


El desempleo, consecuencia de la contracción del sector productivo o de transformación, y del modelo de desarrollo, de manera persistente sitúa al Quindío en los primeros lugares del país. El cuadro extractado del PDD lo expresa con claridad.

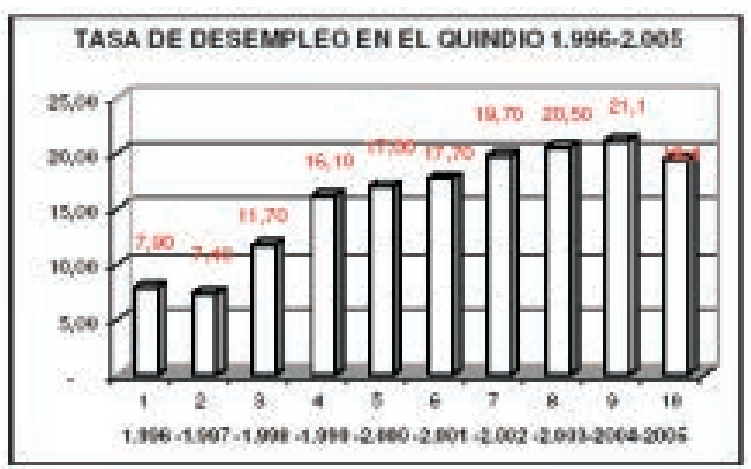

Fuwte OWNE.

En la llamada Gran Encuesta I ntegrada de Hogares del DANE 2007, el departamento en tasa de desempleo, aunque disminuido en varios puntos porcentuales, ocupa el tercer lugar, luego de La Guajira $(15,6)$ y Cesar $(13,9)$, con una tasa de 13,7 y frente a la nacional de 11,1; mientras en subempleo, con tasa de 38 representa la quinta tasa más alta en el país.

La fragilidad económica departamental, como ya se anotó, ha pendido de su anterior fortaleza, el café.

Para la región, el descenso más marcado en el PI B ha sido el quindiano, y precisamente por el mayor núcleo de municipios con alta y media dependencia de esta producción.

Eje Cafetero. Peso promedio del café en PIB municipales.

1993-2002

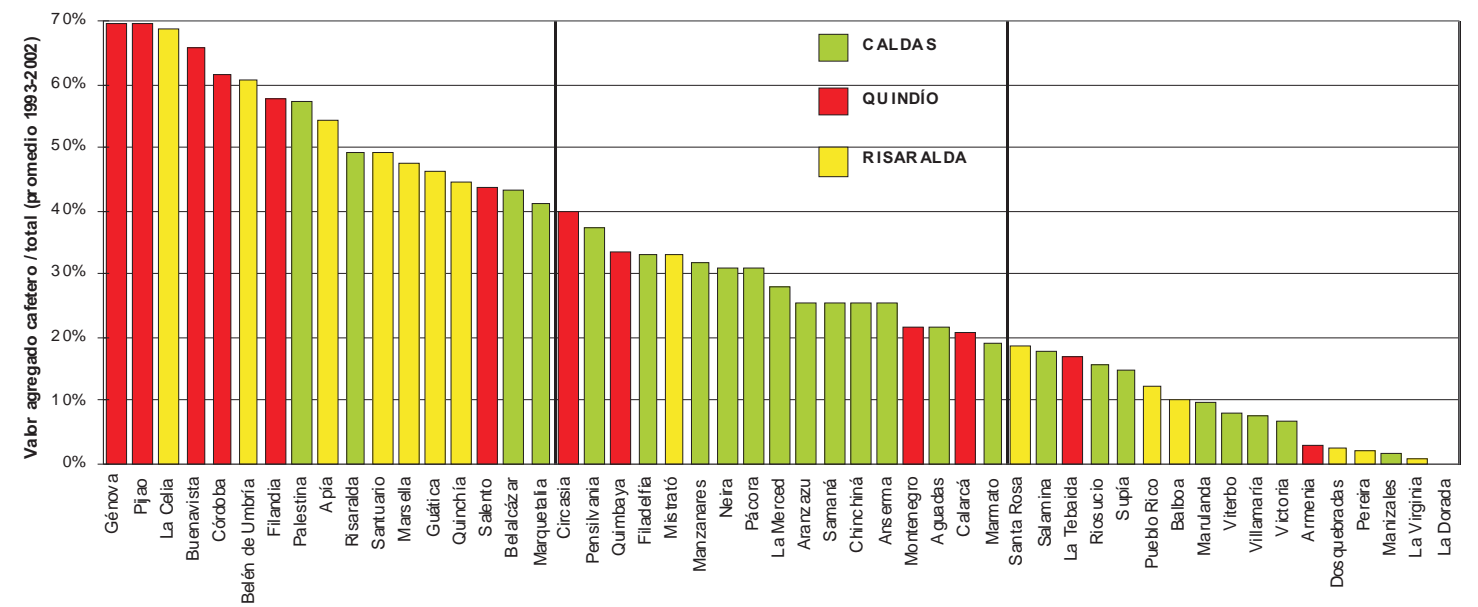

Fuente: Proyecto COL/02/002.

IRDH PNUD.

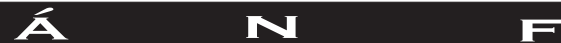

Universidad Autónoma de Manizales 
Diez de los doce municipios del departamento por su vocación agrícola están inscritos en este renglón productivo, aunque el área cultivada venga descendiendo de modo sistemático y sin que otro producto sustituto iguale o se aproxime siquiera de lejos en demanda de trabajo por hectárea como el café.

De acuerdo al consolidado realizado en el estudio sobre educación y gasto público, de la Fundación Luis Felipe Vélez con patrocinio de Save the Children, el comportamiento durante los últimos 25 años en el Departamento se aprecia en esta siguiente gráfica con la contracción de los dos primeros sectores (agropecuario e industria), con muy fuerte descenso del secundario, y una hipertrofia del de servicios y comercio, que no articulado a un proceso de demanda efectiva y división del trabajo, responde a la informalización creciente de amplios sectores sociales abocados al día día, y cuyo dramatismo se observa en la gráfica:

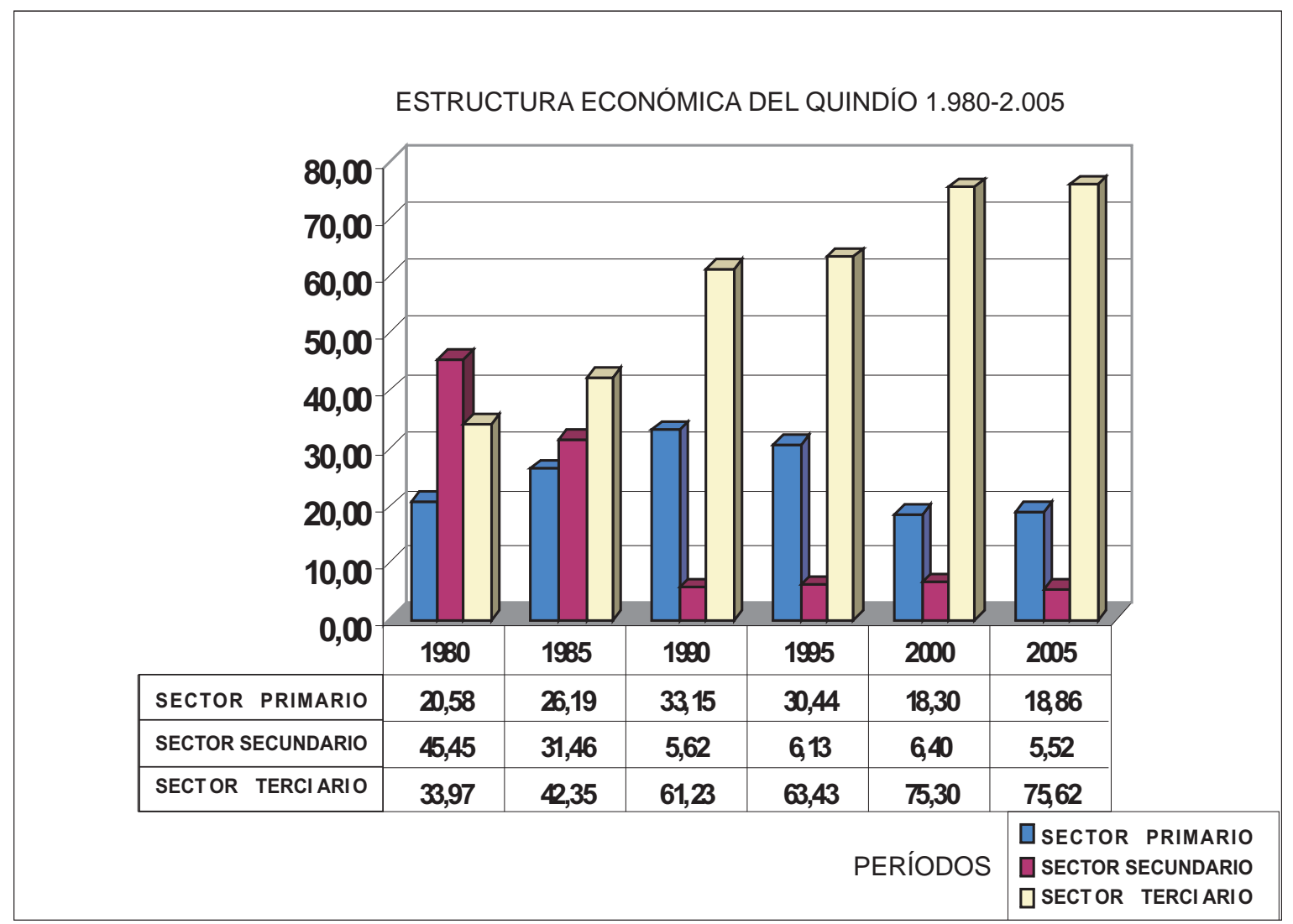

\section{Desnutrición}

En la encuesta nacional de salud ENDS - 2005, capítulo de lactancia y nutrición, para orientar al lector, se encuentran las siguientes definiciones:

- Talla baja para la edad o desnutrición crónica (retraso en el crecimiento lineal). Los niveles de desnutrición crónica, es decir, retardo en el crecimiento en talla para la edad, se determinan al comparar la talla del niño con la esperada para su edad y sexo.

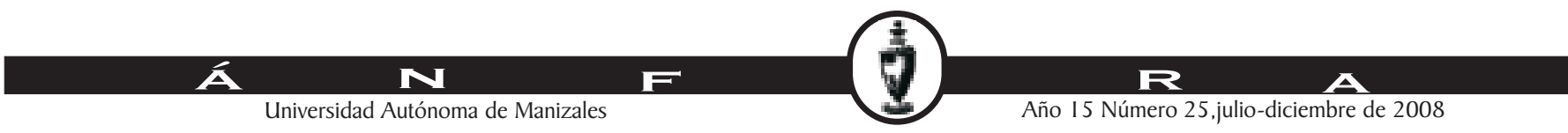


- Peso bajo para la talla o desnutrición aguda (emaciación o delgadez). El bajo peso para la talla es un indicador de desnutrición reciente, conocido también como desnutrición aguda o emaciación, que mide el efecto del deterioro en la alimentación y de la presencia de enfermedades en el pasado inmediato. Se diría que obedece a situaciones de coyuntura.

- Peso bajo para la edad o desnutrición global (o general). El bajo peso para la edad es considerado como un indicador general de la desnutrición, pues no diferencia la desnutrición crónica, que se debería a factores estructurales de la sociedad, de la aguda, que corresponde a pérdida de peso reciente.

En el diagnóstico sobre infancia y adolescencia del departamento del Quindío, destacado como un anexo aparte en el actual Plan de Desarrollo Departamental, por su importancia, se consigna el estado nutricional al 2006, páginas 7 y 8 del mismo documento:

- El $21.6 \%$ de las madres gestantes presenta bajo peso para la edad gestacional.

- De los menores de cinco años que habitan en el departamento del Quindío el 9.6\% tienen prevalencia en desnutrición crónica.

- El $1.45 \%$ de los menores de cinco años tiene prevalencia en desnutrición aguda.

- Con base en los análisis que realiza el Instituto Seccional de Salud (ISSQ), a través del Sistema de Vigilancia Nutricional (SISVAN), en el año 2006 se valoraron 12.532 niños y niñas menores de 12 años donde se observo que el $37.3 \%$ presentan déficit de talla con relación a la edad; el $14.3 \%$ refleja franca desnutrición y el 23\% riesgo leve a desnutrición crónica.

- Riesgo de desnutrición (DNT) crónica. En cuanto al peso-talla el 19.4\% presenta déficit en el peso con relación a su talla; el $4.1 \%$ se clasifican en franca desnutrición; el $\mathbf{1 5 . 3 \%}$ en riesgo leve a desnutrición aguda. Las posibles causas son: elevada energía, malos hábitos alimenticios y trastornos del metabolismo, factor que llevan al sobrepeso y la obesidad, causas que pueden aumentar el factor de riesgo a enfermedades crónicas que hoy son consideradas como problemas de salud pública (hipertensión, diabetes y cardiopatías).

- De acuerdo al seguimiento del SISVAN el sobrepeso en niños y niñas menores a 12 años, para el año 2006 fue de 17.6\%. Se encontraron casos de niños y niñas menores de 5 años con poca estatura y exceso de peso.

- Los municipios que presentan mayor déficit por talla-edad son: La Tebaida, Montenegro, Circasia y Córdoba con intervalos de $62.3 \%$ - 42.6\%. Los municipio de Armenia, Salento, Quimbaya y Calarcá presentan déficit de paso-talla con unos intervalos entre $29.0 \%$ y $20.3 \%$.

El documento cierra, con la consciencia sobre el problema delicado, con el propósito de apuntar a la solución con estas palabras: "Dentro de las políticas incluidas en el Plan de Desarrollo se incluyen programas y metas de alto impacto nutricional".

Si bien es reconocido el grave problema, la suerte de una política social, decíamos, pasa por vectores que no son del todo resorte de la administración pública, o cuyos resortes dependen en gran medida de la estructura social, cuya modificación implica

\section{A N}


a un conjunto de agentes públicos y sociales en función de cambios en el modelo de desarrollo, una movilización social de largo aliento presionando de manera sostenida en el actual juego de fuerzas, hacia un balance distinto.

Operar sobre las consecuencias - no indeseadas- del desarrollo tal y como está establecido, puede morigerarlas; pero revertir las tendencias hacia el aseguramiento de condiciones que no se deslicen por su propia lógica de exclusión y desigualdad hacia las consecuencias que se quieren evitar, es cosa distinta.

Como parte del proceso de la política, el 13 de junio de 2008 en Paipa - Boyacá, los gobernadores de Colombia, entre ellos los de la Ecoregión, en el "VI ENCUENTRO DE GOBERNADORES POR LA INFANCIA, LA ADOLESCENCIA Y LA JUVENTUD" Se comprometieron a implementar y profundizar los procesos de participación en los Planes de Desarrollo, en particular, en lo atinente a infancia y juventud, de los NNAJ (niños, niñas, adolescentes y jóvenes), con claros procesos de "implementación, seguimiento, monitoreo y evaluación", entre cuyas líneas está la de "La participación para garantizar la protección integral de los niños, niñas, adolescentes y jóvenes", en los temas de explotación sexual, maltrato infantil, responsabilidad penal juvenil, trabajo infantil, y violencia generada por grupos armados, con la constitución y puesta en marcha de un observatorio de calidad de vida y participación.

Medida de seguimiento y divulgación que permita establecer de manera oportuna como lo es un sistema de monitoreo, una escala de riesgos y declaratoria de emergencias municipales y focales.

\begin{tabular}{|c|c|c|c|c|c|c|c|c|c|c|}
\hline & INDICADOR & $\begin{array}{l}\text { LÍNEA } \\
\text { BASE }\end{array}$ & AÑO & FUENTE & META & $\begin{array}{l}\text { Explicita } \\
\text { PDD }\end{array}$ & $\begin{array}{l}\text { Implícita } \\
\text { PDD }\end{array}$ & $\begin{array}{l}\text { NO } \\
\text { CONTEMPLADA }\end{array}$ & $\begin{array}{l}\text { INVERSIÓN } \\
\text { POAI }\end{array}$ & $\begin{array}{l}\text { Meta / ODM a } \\
2015 \\
\text { Colombia }\end{array}$ \\
\hline \multirow{6}{*}{$\begin{array}{l}\text { ODM:2 } \\
\text { Lograr la } \\
\text { educación } \\
\text { básica } \\
\text { universal }\end{array}$} & $\begin{array}{l}\text { 1. Tasa de } \\
\text { Analfabetismo } \\
\text { para personas } \\
\text { entre }\end{array}$ & \multirow[t]{2}{*}{1.670} & & \multirow[t]{2}{*}{ PDD } & \multirow[t]{2}{*}{1.169} & & \multirow[t]{2}{*}{$x$} & & & \multirow[t]{2}{*}{$1 \%$} \\
\hline & 15 y 24 años & & & & & & & & & \\
\hline & $\begin{array}{l}\text { 2. Cobertura } \\
\text { para preescolar }\end{array}$ & 4.176 & & PDD & 4.385 & $x$ & & & & \\
\hline & $\begin{array}{l}\text { 3. Cobertura } \\
\text { para básica } \\
\text { primaria }\end{array}$ & 30.043 & & PDD & 30.043 & $x$ & & & & $100 \%$ \\
\hline & $\begin{array}{l}\text { 4. Cobertura } \\
\text { para básica } \\
\text { secundaria }\end{array}$ & 21.715 & & PDD & 21.715 & $x$ & & & & $100 \%$ \\
\hline & $\begin{array}{l}\text { 5. Cobertura } \\
\text { para educación } \\
\text { media }\end{array}$ & 7.125 & & PDD & 7.267 & $x$ & & & & \\
\hline
\end{tabular}

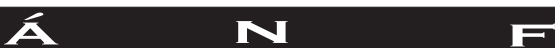

Universidad Autónoma de Manizales 


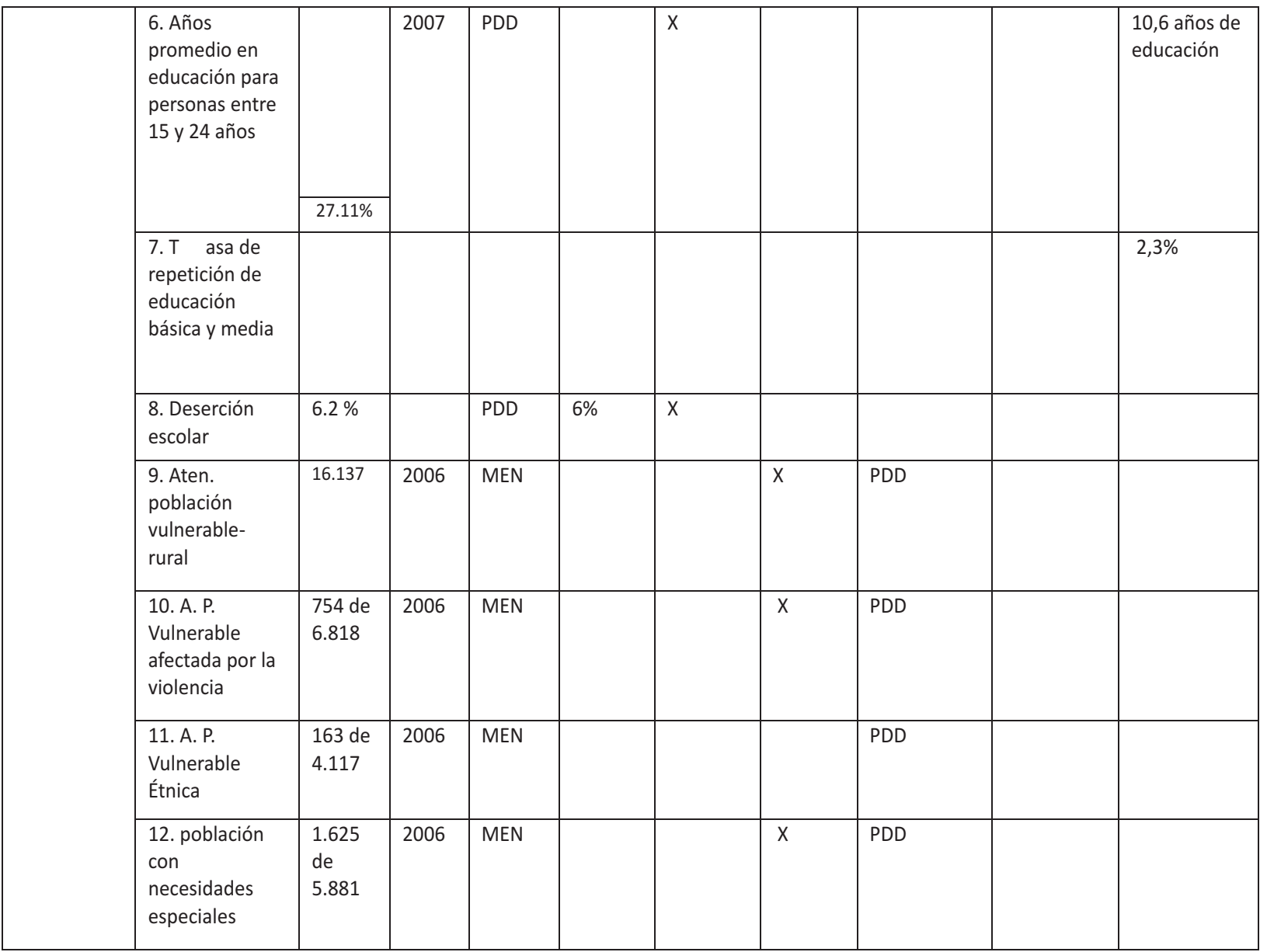

Las metas de la 1 a la 7 son las acordadas para la Ecoregión, y las de la 8 a la 12 son consideradas por el ministerio de Educación Nacional.

“Por tradición el Eje Cafetero había tenido mejores niveles de alfabetismo en comparación con el promedio nacional. Sin embargo, su evolución en la última década hizo que la región perdiera esa ventaja. En efecto la proporción de población adulta que sabe leer y escribir registró una reducción entre 1993 y 2002 en los tres departamentos de la región: en Risaralda pasó de 93\% a 91\%, en Caldas de $92 \%$ a $90 \%$ y en Quindío, el departamento donde más se contrajo, disminuyó de $92 \%$ a $88 \%$. Por el contrario, en el país la tasa aumentó en el mismo período de $90 \%$ a 92\% ."

Este texto corresponde al Informe Regional de Desarrollo Humano para el Eje Cafetero 2004 del PNUD; El analfabetismo ha tocado a los 3 departamentos del Eje, pero con una mayor incidencia para el Quindío.

A $\mathbf{N}$

Universidad Autónoma de Manizales 
En cuanto a cobertura por matrícula, el PDD presenta una evolución positiva de los indicadores:

\begin{tabular}{|l|c|c|c|c|}
\hline \multicolumn{1}{|c|}{ AÑO } & $\mathbf{2 0 0 4}$ & $\mathbf{2 0 0 5}$ & $\mathbf{2 0 0 6}$ & $\mathbf{2 0 0 7}$ \\
\hline Población potencial & 75.169 & 76.014 & 65.727 & 66.100 \\
\hline Matrícula Oficial & 62.346 & 62.678 & 62.224 & 60.494 \\
\hline Matrícula Privada & 2.616 & 2.498 & 2.574 & 2.565 \\
\hline Matrícula Total & 64.962 & 65.176 & 64.798 & 63.059 \\
\hline Cobertura bruta & $86 \%$ & $85 \%$ & $98 \%$ & $95.4 \%$ \\
\hline Variación & & $-1 \%$ & $+13 \%$ & $-2.6 \%$ \\
\hline $\begin{array}{l}\text { Variación anual de } \\
\text { matrícula }\end{array}$ & & +214 & -378 & -1739 \\
\hline
\end{tabular}

Luego de un ascenso fuerte en el año 2006, cae en el 2007. Aún así, en términos generales cobertura y equidad de género en educación son las metas más próximas o alcanzadas ya. Comparando con el MEN:

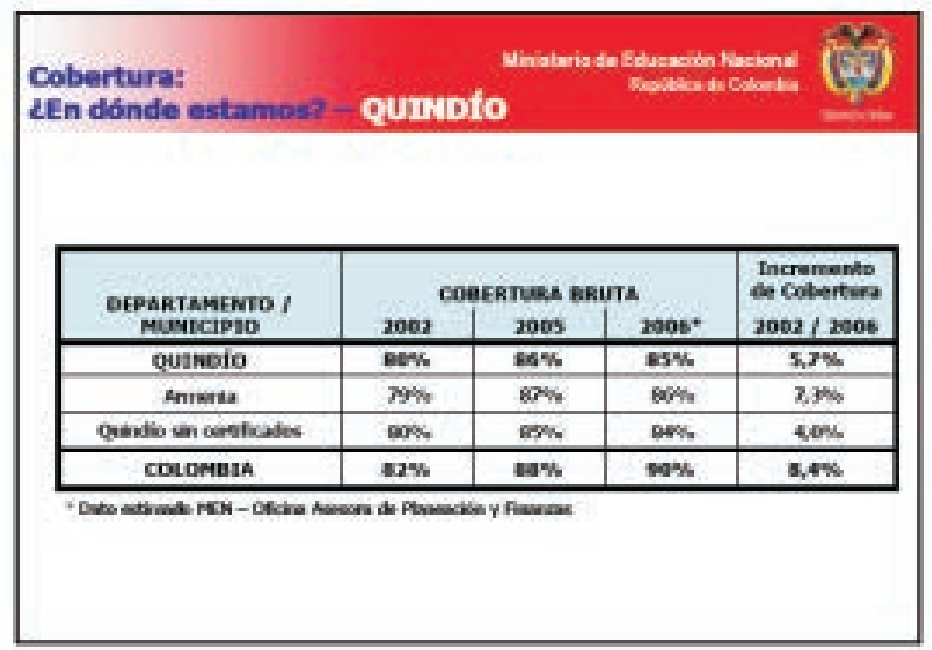

Ver cuadro Cobertura, $¿$ en donde estamos?

Los datos del Departamento y los del MEN difieren en apreciables 10 puntos: La información del MEN debe provenir de los departamentos que se nutren a su vez de los municipios. Los del MEN son estimados, mientras los del Departamento, sin aclararlo en este sentido, se suponen consolidados. Estas disparidades, por ejemplo en un indicador distinto, como el de la mortalidad por causas externas es mucho mayor al comparar entre agencias.

Es necesario un registro controlado y monitoreado, que así pueda garantizar confiabilidad en las cifras, muchas de las cuales, en las series históricas habría que recalcularlas a partir de la línea de base demográfica arrojada por el censo del año 2005: En este caso, al disminuir la población sobre las proyecciones, proporcionalmente las tasas deben aumentar.

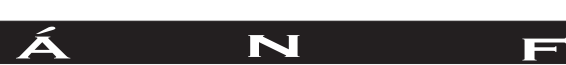

Universidad Autónoma de Manizales

\section{$\mathbf{R}$}

Año 15 Número 25,julio-diciembre de 2008 


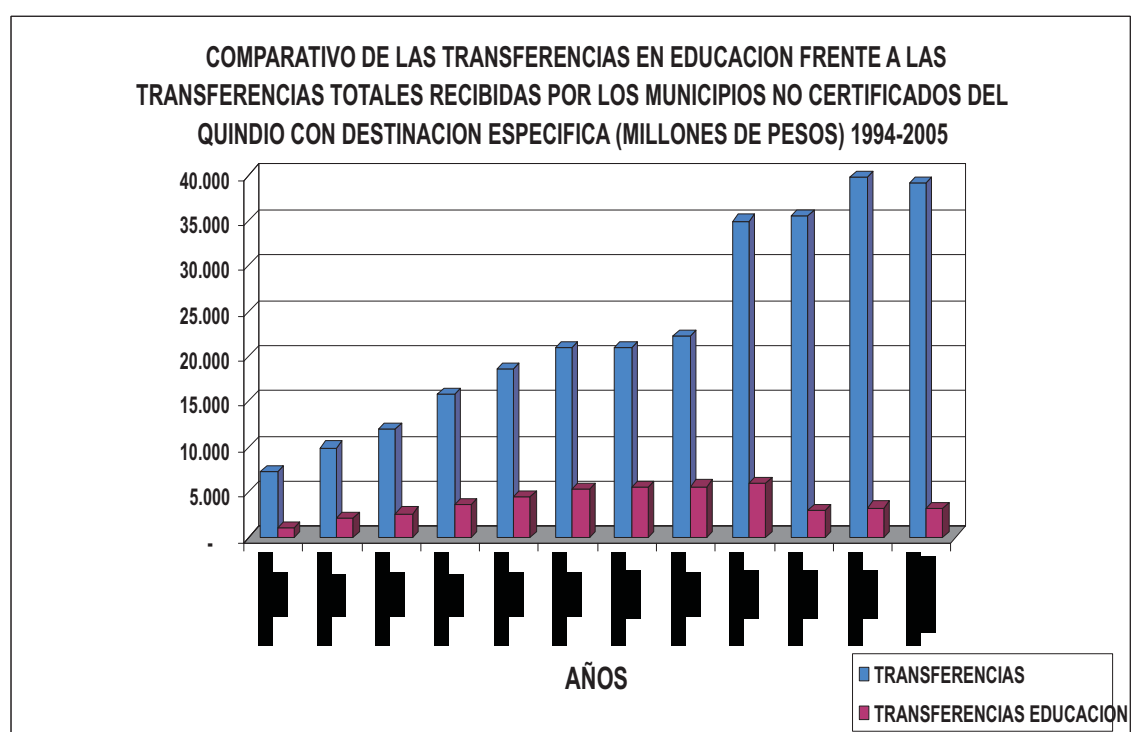

Fuente: DNP (tomado de Estudio Fundación Luis Felipe Vélez.)

Fuente: DNP (tomado de estudio de la Fundación Luis Felipe Vélez - save The Children y patrocinadores.)

En cuanto a las transferencias, de acuerdo a las ponderaciones realizadas en el estudio que las presenta en el cuadro, la caída para el sector educativo tendría diversas interpretaciones, entre las que son resultado de los cambios en la contratación y en las directrices nacionales. Se debe valorar el significado decreciente de estas transferencias en los efectos sobre la cobertura y la calidad conceptuada como parte de la calidad de vida para la que los estándares de competencias son opacos.

La educación es de las metas en los objetivos, miradas en cobertura total y de género, por el proceso histórico, de las más "felices" en estándares, y de las más infelices en inclusión. Y por deserción en los primeros años, la masculina expresa una dinámica familiar de vinculación precoz y forzada al trabajo de una parte, y de otra, el abandono por acceso a rentas que aunque mínimas en gran proporción, hacen la diferencia entre dependencia e independencia personal para la presentación en el mundo social.

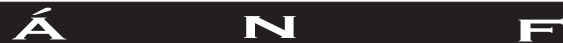

Universidad Autónoma de Manizales 


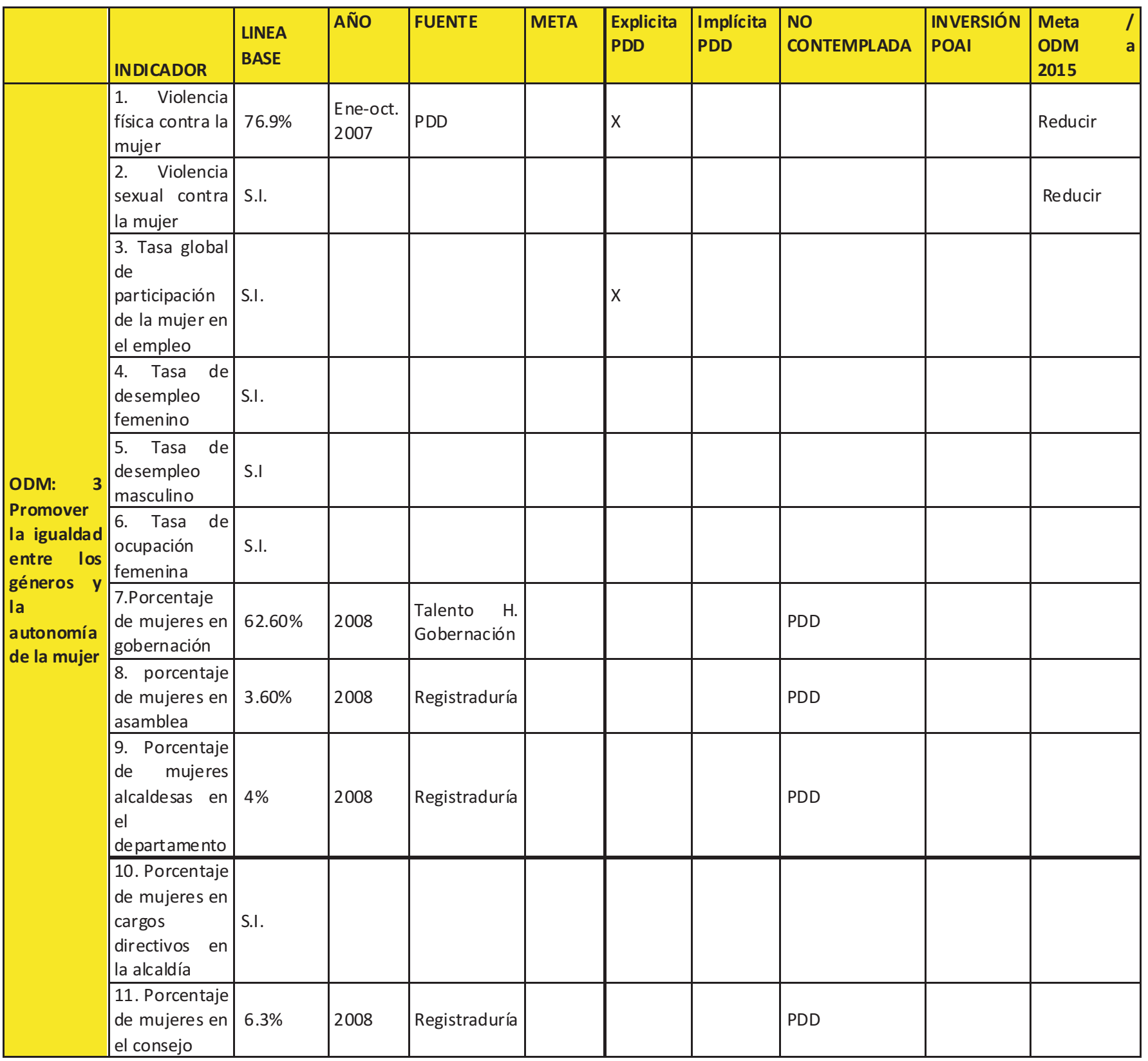

En el Plan de Desarrollo Departamental, en el tema de la equidad de género se ha consignado de manera taxativa lo siguiente:

\section{Equidad de género}

En el departamento, la población total de mujeres es de 172.349 , en un rango de edad 15 a 64 años, lo que equivale al $29.8 \%$. Los factores de riesgo que pueden afectar esta

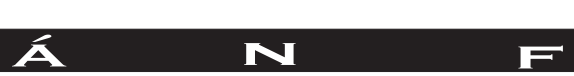


población son los siguientes: bajo nivel de ingresos de las mujeres cabeza de hogar del sector urbano y rural, el bajo nivel educativo, la falta de oportunidades laborales, la descomposición del núcleo familiar, la violencia intrafamiliar y la crisis cafetera, han contribuido a que la responsabilidad de los hogares recaiga sobre ellas.

Durante los meses de enero a octubre del 2007, de los 1258 casos reportados de violencia, 967 casos, pertenecen a mujeres, lo que equivale al $76.9 \%$ diferente al $23.1 \%$, que corresponde a 291 casos reportados del sexo masculino. Lo que demuestra la prevalencía de la agresión contra la mujer. De los 1258 casos reportados, 752 caen en la categoría de agredidos según el grupo de edad de 15 a 59 años, igual a $59.7 \%$. (I.S.S.Q.). A pesar de existir a nivel nacional la política pública para la equidad de género, no se ha establecido a nivel departamental junto con la de reconocimiento a la diversidad sexual. La mujer, al igual que el hombre, y la población LGBT (Lesbiana, gay, bisexuales y transgeneristas), son víctimas de discriminación, entendido como el trato diferente a situaciones iguales. Como la segregación puede ser directa e indirecta, es necesario enfrentar esta situación en aras de crear una sociedad más democrática, pacifica e incluyente.

Se presenta un reconocimiento explícito a la ausencia de una política en equidad de género, al igual que a la de diversidad sexual, para lo cual se adoptarán los mecanismos para subnasar - en perspectiva participativa, este vacío como reza en el apartado 2.1.4 del PDD "Dimensión especial de Género". Y se reconoce además en el PDD que en adultos mayores, la composición por sexo alcanza al 54\%:

Gran parte de ellos sobreviven en condiciones de pobreza, abandono familiar, desempleo, sedentarismo, inactividad, enfermedades mentales y cardiovasculares, desnutrición, abandono familiar, insuficiencia de oportunidades de trabajo y ocupación del tiempo libre; esta situación se ve agravada por la imposibilidad institucional de prestar una atención integral a la totalidad de los adultos mayores y al no reconocimiento de los valores y derechos de estas personas. (Subrayado nuestro).

Entre los problemas de mayor magnitud e impacto sobre los hogares, y entre ellos los de las clases subordinadas, el de jefatura femenina es el más crónico y el que reproduce de manera más férrea el circulo vicioso de la pobreza, y en este problema el hombre contribuye como protagonista de primera línea con la inasistencia alimentaria, una de las conductas por omisión tipificada como delito de mayor ocurrencia en Colombia, problema complejo de arreglos de pareja que desencadenan una corriente de desprotección a los menores y que no está consignada en el CONPES 091 para los ODM en el país.; o por causas como el desplazamiento forzado.

En el porcentaje de empleo y calidad de ingreso, la gobernación ha superado de manera amplia el estándar esperado de 33\%. Sin embargo, como lo acabamos de ver, frente a los ingresos y el empleo, el concepto de género resulta más insidioso para las mujeres, pero englobado por el mayor de (in) equidad social, en el que las clases subalternas padecen de modo explícito el rigor del las consecuencias económicas negativas.

Los más sensibles cuestionamientos a este objetivo del milenio provienen del lado de la mujer; así, desde Brasil, Ana María Soares, Secretaria adjunta de la Red Feminista de Salud, (113 organizaciones) afirma que: “...Es mejor luchar por el cumplimiento de los compromisos asumidos en las conferencias de El Cairo - 1994- y de Beijing -1995-, que son más amplios y mejor articulados con otras cuestiones del desarrollo, (que)

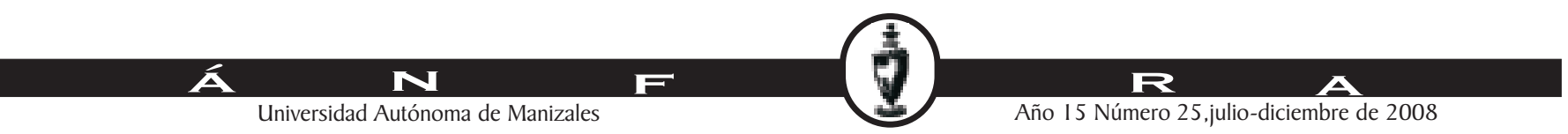


adoptaron planes de acción para afirmar la igualdad de género y variados derechos humanos, especialmente los sexuales y reproductivos, relacionándolos con el combate a la pobreza".

En el mismo artículo, se relaciona a Sonia Correa, "coordinadora de investigación en Salud y Derechos Sexuales y Reproductivos de DAWN, una red mundial. Más allá de ese reduccionismo y de las simplificaciones distorsionadoras, el retroceso de los objetivos se extiende también a la escasa participación de la sociedad civil, que fue muy pequeña en la Cumbre del Milenio celebrada en septiembre de 2000 en comparación con las conferencias del ciclo social de los años 90". (Portal de las Mujeres Latinoamericanas. 05/09/2005).

De "Radio Internacional Feminista - FIRE- de septiembre de 2005, IPS Noticias, se reseña la siguiente postura sobre la equidad de género, y las consecuencias en los objetivos del milenio, que vale la pena reproducir en parte para las y los lectores:

“EI martes 23, participantes en una reunión convocada por Mujeres Para Mujeres, un grupo de investigación y estudio de Bangladesh, se mostraron cautelosas y escépticas sobre las Metas del Milenio, cuya máxima prioridad es reducir la pobreza".

"Mientras que los ocho Objetivos del Milenio tienen plazos y son concretos, con 18 metas y 48 indicadores específicos para medir los logros, carecen de un enfoque basado en los derechos", dijo a IPS Salma Khan, integrante del comité de la ONU para el cumplimiento de la Convención. Las metas "no perciben los derechos humanos de las mujeres como un objetivo de desarrollo", afirmó.

El tercer objetivo del milenio es promover la igualdad de género y dar poder a las mujeres, pero el único especificado es eliminar la desigualdad de género en la educación primaria y secundaria para este año y en la universitaria y terciaria para 2015, resaltó Khan.

Esto no sólo limita, sino que conlleva el riesgo de dar carta blanca a los gobiernos, indicó. "Por ejemplo, Bangladesh ya ha logrado la igualdad de género, por lo menos en términos de inscripciones (en las escuelas), y nuestro gobierno podría salir airoso con eso".

Además, en ausencia de especificación, los otros objetivos pueden no abordar las discriminaciones con base en el género", dijo Khan. "La meta establecida para erradicar la pobreza extrema sólo habla de ingresos, sin mencionar la perspectiva de género esencial", agregó.

Uno de los temores era que, demasiado énfasis en los Objetivos del Milenio distraería al gobierno de los compromisos de la Convención y del Plan de Acción de Beijing, que identificó 12 áreas críticas detalló estrategias para avanzar hacia la igualdad, la no discriminación y los derechos humanos de las mujeres.

"Guiándonos por la Conferencia de Beijing, trabajamos durante dos años ayudando al gobierno a preparar nuestro plan de acción para el país", señaló Mahmuda Islam, presidenta de Mujeres para Mujeres. "Nosotras ya tenemos estrategias y objetivos muy claros. Ahora hay presión de los donantes para priorizar los Objetivos de Desarrollo y tememos que el Plan resulte marginado del proceso". "Seis importantes cumbres de la ONU llevadas a cabo en los años 90 se habían basado en la Declaración Universal de Derechos Humanos y habían llevado una agenda sustancial de no discriminación e igualdad de género", dijo

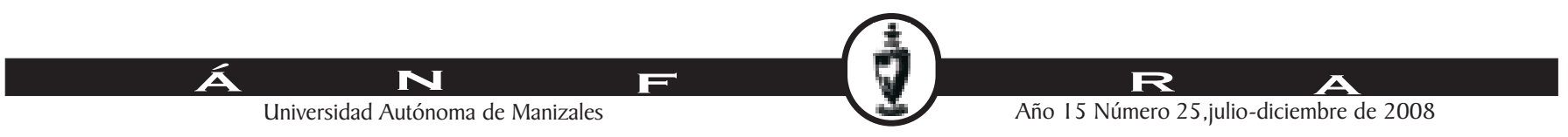


Khan. "Los Objetivos del Milenio aparentemente evitan las premisas establecidas por las conferencias previas y suavizan las preocupaciones".

Wassel Bin Sadat, investigador en el Centro para el Diálogo de Políticas, consideró demasiado modestas las Metas del Milenio e instó a los activistas a identificar objetivos y asuntos específicos de Bangladesh. "El enfoque del 'talle único para todos' no va a funcionar".

"No se puede tener los mismos objetivos, por ejemplo, para la región de África subsahariana y para Asia austral", concordó Khan. "Las culturas y las prácticas varían, y el estado de crecimiento y desarrollo difiere ampliamente". Una de las finalidades de la reunión fue informar sobre los Objetivos de Desarrollo para el Milenio y sus fallas.

"El movimiento para el desarrollo del milenio es auspiciado por la ONU, pero sus ingenieros son los países ricos", dijo la activista Farida Akhter. "Y sólo podría despegar con la sanción del Banco Mundial y el Fondo Monetario Internacional. No debemos olvidar quién está detrás y con qué intereses", sentenció.

Mientras tanto, Bangladesh está por finalizar su Propuesta de Estrategia para Reducción de la Pobreza, en respuesta al proceso iniciado por el Banco Mundial y el Fondo Monetario Internacional.

Cabe una pregunta final: ¿la participación porcentual de las mujeres en cargos públicos por generación espontánea producirá un vuelco en las condiciones de reproducción socioestructurales? Entre nosotros se puede consultar a Cecilia López montaño: Globalización, pobreza y las metas del milenio desde la perspectiva de género.

\begin{tabular}{|c|c|c|c|c|c|c|c|c|c|c|}
\hline & INDICADOR & LÍNEA BASE & AÑO & FUENTE & META & $\begin{array}{l}\text { Explicita } \\
\text { PDD }\end{array}$ & $\begin{array}{l}\text { Implícita } \\
\text { PDD }\end{array}$ & $\begin{array}{l}\text { NO } \\
\text { CONTEMPLADA }\end{array}$ & $\begin{array}{l}\text { INVERSIÓN } \\
\text { POAI }\end{array}$ & $\begin{array}{|ll|}\text { Meta } & \text { / } \\
\text { ODM } & \text { a } \\
2015 & \\
\end{array}$ \\
\hline \multirow{8}{*}{$\begin{array}{l}\text { ODM: } \quad 4 \\
\text { Reducir la } \\
\text { mortalidad } \\
\text { infantil }\end{array}$} & $\begin{array}{l}\text { 1. Tasa de } \\
\text { mortalidad en } \\
\text { menores de } 5 \\
\text { años por mil } \\
\text { nacidos }\end{array}$ & $16.22 \%$ & & PDD & $\begin{array}{l}\text { Menor a } \\
15 \%\end{array}$ & $x$ & & & & $17 \times 1000$ \\
\hline & $\begin{array}{l}\text { 2. Tasa de } \\
\text { mortalidad en } \\
\text { menores de } 1 \\
\text { año por mil } \\
\text { nacidos }\end{array}$ & $11.59 \%$ & & PDD & $\begin{array}{l}\text { Menor a } \\
11 \%\end{array}$ & $x$ & & & & $14 \times 1000$ \\
\hline & \begin{tabular}{|l|} 
3. Vacunación \\
para menores \\
de 5 años \\
(triple viral ) \\
\end{tabular} & $88.2 \%$ & & PDD & $95 \%$ & $x$ & & & & $95 \%$ \\
\hline & $\begin{array}{l}\text { 4. Vacunación } \\
\text { para menores } \\
\text { de } 5 \text { años } \\
\text { (DTP) tres } \\
\text { dosis }\end{array}$ & & & & & & & & & $95 \%$ \\
\hline & 5. Antipolio & $84.1 \%$ & & PDD & $95 \%$ & $x$ & & & & $95 \%$ \\
\hline & \begin{tabular}{|l|}
6. \\
Pentavalente
\end{tabular} & 84.15 & & PDD & $95 \%$ & $x$ & & & & $95 \%$ \\
\hline & 7. B.C.G. & $100 \%$ & & PDD & $100 \%$ & & & & & $95 \%$ \\
\hline & 8. hepatitis B & $100 \%$ & & PDD & $100 \%$ & & & & & $95 \%$ \\
\hline
\end{tabular}

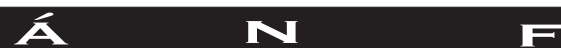

Universidad Autónoma de Manizales 
De la Seccional de Salud del Quindío, el siguiente cuadro presenta la serie de 6 años llegando al 2006. Estas cifras adelantan sobre las primeras metas del objetivo, aun cuando en las de cobertura de vacunación elcamino a recorrer implica unos programas más intensos.

MORTALIDAD PERINATAL, INFANTIL Y MATERNA

QUINDÍO 2001 - 2006

\begin{tabular}{|l|l|l|l|l|l|l|}
\hline \multirow{2}{*}{ AÑO } & \multicolumn{2}{l}{ PERINATAL } & \multicolumn{2}{l|}{ INFANTIL } & \multicolumn{2}{l|}{ MATERNA } \\
\cline { 2 - 7 } & No. & Tasa & No. & Tasa & No. & Tasa \\
\hline 2001 & 189 & 17,5 & 191 & 19,8 & 8 & 0,8 \\
\hline 2002 & 152 & 17,2 & 154 & 17,4 & 5 & 0,6 \\
\hline 2003 & 151 & 17,7 & 155 & 18,2 & 2 & 0,2 \\
\hline 2004 & 129 & 18,2 & 118 & 14,8 & 5 & 0,6 \\
\hline 2005 & 153 & 20,5 & 87 & 11,2 & 7 & 0,9 \\
\hline 2006 & 118 & 16,6 & 93 & 13,1 & 0 & 0,0 \\
\hline
\end{tabular}

Una vez alcanzadas y superadas las metas en este objetivo, ¿̇la infancia está bién?. Por supuesto que los objetivos han sido concebidos en bloque para su desarrollo, implicando con ello la transformación de aquellas metas estructuralmente determinadas, entre ellas las de desnutrición crónica.

Las anotaciones críticas de las mujeres valen para todos los objetivos, y para los géneros, no para uno solo, aunque el énfasis señala una crónica desigualdad histórica. Lo señalamos acudiendo a la experiencia de la reconstrucción del Quindío luego del terremoto de 1999: El paso de la informalidad a la formalidad de asentamientos planificados, aún en los estratos denominados bajos para la población relocalizada significó una abrupta enseñanza para las restricciones ya impuestas en sus modos de vida, que desde la informalidad -la exclusión- les permitieron la construcción de unos circuitos de sobrevivencia anclados en unas territorialidades también informales y de las que se surtían en apreciable proporción extrayendo valor agregado y "ventajas comparativas" de esta situación, al explotar zonas verdes de cañada, construcciones frágiles pero amplias con arriendo y sub - arriendo; a la vez que colgarse de servicios públicos. El ascenso a la formalidad resultó en unas severas rupturas de sus estrategias de sobreviviencia, cuyos efectos multiplicadores cubrieron y cubren a todas las generaciones de estas porciones de habitante.La situación así configurada demanda, en política, la previsión de condiciones de soporte, que el optimismo en la mejora de unos indicadores puede representar la desmejora no solo en otros; sino llevarlos más allá hacia el límite casi nulo de posibilidades de acción "exitosa" en la sobrevivencia.

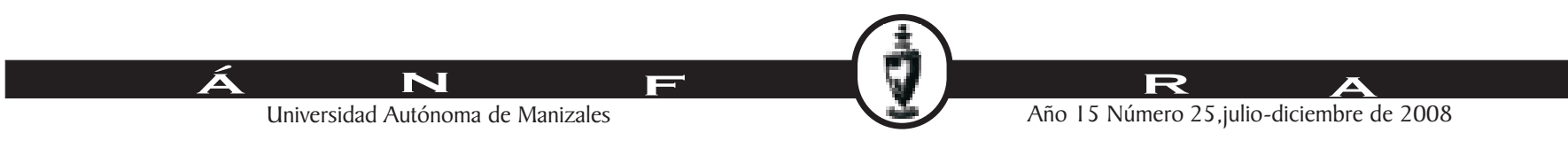




\begin{tabular}{|c|c|c|c|c|c|c|c|c|c|c|}
\hline & INDICADOR & LÍNEABASE & AÑ & FUENIE & META & $\begin{array}{l}\text { Expliata } \\
\text { PDD } \\
\end{array}$ & \begin{tabular}{|l} 
Implíáta \\
PDD \\
\end{tabular} & NOCONIENPLADA & $\begin{array}{l}\text { IMERSIÓN } \\
\text { POA }\end{array}$ & \begin{tabular}{|l|} 
Meta / CDM \\
a2015 \\
\end{tabular} \\
\hline \multirow{10}{*}{$\begin{array}{lr} & \\
\text { ODM } & 5 \\
\text { Majorar } & \text { ba } \\
\text { salud sexud y } \\
\text { reproductiva }\end{array}$} & $\begin{array}{ll}1 & \text { Tasa de } \\
\text { mortalidad } \\
\text { materna por cien } \\
\text { mil nadidos vivos }\end{array}$ & 53.29 & & PDD & Menor a50 & $x$ & & & & $\begin{array}{lll}45 & x & 1000 \\
\text { radidos vivos }\end{array}$ \\
\hline & $\begin{array}{l}2 \text { Porcentaje de } \\
\text { mijeres con } \\
\text { autro o mas } \\
\text { contrdes } \\
\text { prenatales }\end{array}$ & 55.67 & 2007 & Seccional desalud & & & & & & \\
\hline & $\begin{array}{l}\text { 3. Atención } \\
\text { institurional al } \\
\text { parto }\end{array}$ & $98.96 \%$ & 2007 & Seccional desalud & & & $x$ & & & $95 \%$ \\
\hline & $\begin{array}{l}\text { 4. Atención por } \\
\text { personal } \\
\text { calificadb }\end{array}$ & 7.078 & 2007 & Seccional desalud & & & $x$ & & & $95 \%$ \\
\hline & $\begin{array}{l}\text { 5. Prevalenia } \\
\text { del uso moderno } \\
\text { de los } \\
\text { mótedodos } \\
\text { planificación de }\end{array}$ & & & & & & $x$ & & & \\
\hline & $\begin{array}{l}\text { 6. Porcentaje de } \\
\text { addlescentes } \\
\text { madres o en } \\
\text { enbarzzo }\end{array}$ & 1894 & 2007 & Seccional desalud & & & $x$ & PDD & & \\
\hline & $\begin{array}{l}\text { 7. Nortalidad } \\
\text { por cáncer de de } \\
\text { ardlor uterino } \\
\text { por den mil } \\
\text { mijeres }\end{array}$ & 14.1 & & PDD & 121 & $x$ & & $\mathrm{x}$ & & \\
\hline & $\begin{array}{l}8 \text { Nortalidad } \\
\text { por cáncer de } \\
\text { aullor iterino } \\
\text { por den mil } \\
\text { mijeres }\end{array}$ & 26 & 2007 & Seccional desalud & & & & PDD & & \\
\hline & $\begin{array}{|lr|}\text { 9. } & \text { mortalidad } \\
\text { por } & \text { cáncer de } \\
\text { mama }\end{array}$ & 40.0 & & PDD & 40 & $x$ & & $x$ & & \\
\hline & $\begin{array}{lr}10 & \text { mortalidad } \\
\text { por } & \text { síflis } \\
\text { getacional } & x \\
1000 \mathrm{NV} \text { r } & \end{array}$ & 10.3 & & PDD & Menora6 & $x$ & & $\mathrm{x}$ & & \\
\hline
\end{tabular}

Este Objetivo, en su primera meta va en camino de lograrse al 2015. Las de atención institucional calificada ya se han superado, lo que indica que en varias metas de los objetivos, los institutos están en un nivel de eficacia y eficiencia, en lo que de ellos depende, alto.

\section{A N}


El Informe Regional de Desarrollo Humano explicita esta cualidad: mientras se contrae de manera sistemática la acción de asistencia técnica y social de la Federación de Cafeteros, se amplia la de cubrimiento y asistencia en salud de las administraciones municipales y la departamental, con programas de extensión territorial.

Esta cualificación entraña lo que hoy con denominación casi esotérica se plantea como sostenibilidad, otrora consolidación de procesos, que como bien público, puede mantenerse, y la razón de esta racionalidad es la de una histórica inversión social tributando al Estado, bajo la forma de soporte a un derecho fundamental, que exige para sí la calidad de público.

\begin{tabular}{|c|c|c|c|c|c|c|c|c|c|c|}
\hline & INDICADOR & \begin{tabular}{|l} 
LÍNEA \\
BASE \\
\end{tabular} & AÑ̃O & FUENTE & META & \begin{tabular}{|l|} 
Explicita \\
PDD
\end{tabular} & \begin{tabular}{|l|} 
Implícita \\
PDD
\end{tabular} & \begin{tabular}{|l|} 
NO \\
CONTEMPLADA
\end{tabular} & \begin{tabular}{|l|} 
INVERSIÓN \\
POAI
\end{tabular} & \begin{tabular}{|l}
$\begin{array}{l}\text { Meta / ODM } \\
\text { a } 2015\end{array}$ \\
\end{tabular} \\
\hline \multirow{6}{*}{$\begin{array}{l}\text { ODM: } 6 \\
\text { Combatir } \\
\text { el VIH / } \\
\text { SIDA ,la } \\
\text { malaria y el } \\
\text { dengue }\end{array}$} & $\begin{array}{l}\text { 1. Prevalencia } \\
\text { de VIH Sida } \\
\text { (15 a } 49 \text { años } \\
\text { l }\end{array}$ & 119 & 2007 & $\begin{array}{l}\text { Seccional de } \\
\text { salud }\end{array}$ & & & $\mathrm{x}$ & PDD & & $\begin{array}{l}\text { prevalencia } \\
\text { por debajo } \\
\text { de 1,2\% }\end{array}$ \\
\hline & \begin{tabular}{|l|} 
2. Cobertura \\
de terapia \\
antirrectoviral
\end{tabular} & & & & & & $x$ & & & al $82 \%$ \\
\hline & \begin{tabular}{|l|} 
3. Casos de \\
muerte por \\
malaria \\
\end{tabular} & & & & & & & & & $\begin{array}{l}\text { reducirla en } \\
85 \%\end{array}$ \\
\hline & \begin{tabular}{|l|} 
4. Casos de \\
muerte por \\
dengue \\
\end{tabular} & & & & & & & & & $\begin{array}{l}\text { reducir en } \\
80 \%\end{array}$ \\
\hline & \begin{tabular}{|l|} 
5. Infestación \\
de Aedes \\
aeqypti de los \\
municipios \\
categoría \\
especial \\
\end{tabular} & & & & & & & & & \\
\hline & $\begin{array}{l}6 . \\
\text { Tuberculosis x } \\
100.000 \\
\text { habitantes }\end{array}$ & 60 & & PDD & $\begin{array}{l}\text { Menor a } \\
60\end{array}$ & $x$ & & & & \\
\hline
\end{tabular}

La disponibilidad de la Seccional de Salud para responder a las necesidades de información en general y para este objetivo en particular no tiene dudas. No obstante, las aclaraciones sobre las estadísticas de VIH/SIDA que exigen una lectura cualificada por las diferencias entre notificados y confirmados; en este caso el número de 119 están por notificación pero están en proceso de confirmación. Entre las explicaciones aportadas se encuentra la de la diferencia entre atención al paciente, y residencia del paciente, que no son de manera sistemática equivalentes, varios de los cuales tienen residencia por fuera del departamento pero se tratan en él.

En mortalidad por VIH a 2006 se registran 67.

A N N F Universidad Autónoma de Manizales 
En el cuadro siguiente se presentan las enfermedades de notificación obligatoria:

ENFERMEDADES DE NOTIFICACION OBLIGATORIA QUINDIO 2006

\begin{tabular}{|c|c|c|c|c|c|c|c|c|c|c|c|c|c|c|c|c|}
\hline Municipio & $\begin{array}{l}\text { Dengue } \\
\text { Clasico }\end{array}$ & $\begin{array}{l}\text { Dengue } \\
\text { Hemorragico }\end{array}$ & $\begin{array}{l}\text { Malaria } \\
\text { Falciparum }\end{array}$ & $\begin{array}{l}\text { Malaria } \\
\text { Vivax }\end{array}$ & Sarampion & Rubeola & Parotiditis & Tosferina & \begin{tabular}{|l|} 
Paralisis \\
Flacida
\end{tabular} & $\begin{array}{l}\text { Meningitis } \\
\text { Hemophilus }\end{array}$ & $\begin{array}{l}\text { Hepatitis } \\
\text { B }\end{array}$ & \begin{tabular}{|l|} 
Tétano \\
Néonatal
\end{tabular} & \begin{tabular}{|l|} 
T.B.C. \\
Todas \\
Formas \\
\end{tabular} & Lepra & $\begin{array}{l}\text { Sifilis } \\
\text { Congénita }\end{array}$ & $\begin{array}{l}\text { VIH } \\
\text { SIDA }\end{array}$ \\
\hline & Casos & Casos & Casos & Casos & Casos & Casos & Casos & Casos & Casos & Casos & Casos & Casos & Casos & Casos & Casos & Casos \\
\hline Armenia & 646 & 5 & 5 & 29 & 1 & 3 & 2 & 0 & 0 & 0 & 3 & 0 & 129 & 0 & 20 & 67 \\
\hline Buenavista & 2 & 0 & 0 & 0 & 0 & 0 & 0 & 0 & 0 & 0 & 0 & 0 & 0 & 0 & 0 & 1 \\
\hline Calarcá & 326 & 0 & 0 & 9 & 0 & 0 & 1 & 0 & 0 & 0 & 1 & 0 & 25 & 0 & 2 & 13 \\
\hline Circasia & 9 & 0 & 0 & 2 & 0 & 1 & 0 & 0 & 0 & 0 & 3 & 0 & 15 & 0 & 1 & 8 \\
\hline Cordoba & 138 & 1 & 1 & 3 & 0 & 0 & 1 & 0 & 0 & 0 & 0 & 0 & 2 & 0 & 0 & 1 \\
\hline Filandia & 11 & 0 & 1 & 1 & 0 & 0 & 5 & 0 & 0 & 0 & 0 & 0 & 2 & 0 & 0 & 1 \\
\hline Génova & 18 & 0 & 0 & 1 & 0 & 0 & 0 & 0 & 0 & 0 & 0 & 0 & 3 & 0 & 0 & 4 \\
\hline La Tebaida & 386 & 0 & 1 & 13 & 0 & 0 & 4 & 0 & 0 & 1 & 0 & 0 & 12 & 0 & 4 & 3 \\
\hline Montenegro & 140 & 1 & 3 & 17 & 0 & 0 & 0 & 0 & 0 & 0 & 2 & 0 & 24 & 0 & 7 & 7 \\
\hline Pijao & 3 & 0 & 0 & 2 & 0 & 0 & 3 & 5 & 0 & 0 & 0 & 0 & 1 & 0 & 0 & 1 \\
\hline Quimbaya & 230 & 0 & 4 & 25 & 0 & 0 & 3 & 0 & 0 & 0 & 1 & 0 & 30 & 1 & 1 & 7 \\
\hline Salento & 1 & 0 & 0 & 1 & 0 & 0 & 2 & 0 & 0 & 0 & 1 & 0 & 1 & 0 & 0 & 1 \\
\hline TOTAL & 1.910 & 7 & 15 & 103 & 1 & 4 & 21 & 5 & 0 & 1 & 11 & 0 & 244 & 1 & 35 & 114 \\
\hline
\end{tabular}

$\begin{array}{ll}\text { Fuente: } & \text { Vigilancia en Salud Pública I.S.S.Q. } \\ & \text { a } 31 / 12 / 2006\end{array}$

\begin{tabular}{|c|c|c|c|c|c|c|c|c|c|c|}
\hline & INDICADOR & $\begin{array}{l}\text { LÍNEA } \\
\text { BASE }\end{array}$ & AÑo & FUENTE & META & $\begin{array}{l}\text { Explicita } \\
\text { PDD }\end{array}$ & $\begin{array}{l}\text { Implícita } \\
\text { PDD }\end{array}$ & $\begin{array}{l}\text { NO } \\
\text { CONTEMPLADA }\end{array}$ & $\begin{array}{l}\text { INVERSIÓN } \\
\text { POAI }\end{array}$ & $\begin{array}{l}\text { Meta / } \\
\text { ODM a } \\
2015\end{array}$ \\
\hline \multirow{9}{*}{$\begin{array}{l}\text { ODM: } 7 \\
\text { Garantizar la } \\
\text { sostenibilidad } \\
\text { ambiental }\end{array}$} & $\begin{array}{l}\text { 1. Tasa de } \\
\text { reforestación } \\
\text { en hectáreas } \\
\text { anuales }\end{array}$ & & & & & & & & & $\begin{array}{l}30.000 \mathrm{H} @ \\
\text { año }\end{array}$ \\
\hline & $\begin{array}{l}\text { 2. Hectáreas } \\
\text { protegidas con } \\
\text { el sistema de } \\
\text { parques } \\
\text { nacionales } \\
\text { naturales }\end{array}$ & $\begin{array}{l}33.147 \\
\text { H@ } \\
\text { Cuenca } \\
\text { Río La } \\
\text { Vieja }\end{array}$ & & PAT CRQ & $\begin{array}{l}\text { PAT/GAR } \\
\text { Programas }\end{array}$ & & $x$ & & & $\begin{array}{l}\text { 165.000 H@ } \\
\text { nuevas. }\end{array}$ \\
\hline & $\begin{array}{l}\text { 3. Planes de } \\
\text { manejo } \\
\text { formulados } \\
\text { socialmente } \\
\text { aceptados }\end{array}$ & & & & & & $x$ & & & \\
\hline & $\begin{array}{l}\text { 4.Consumo de } \\
\text { sustancias } \\
\text { agotadoras de } \\
\text { la capa de } \\
\text { ozono (SAO) } \\
\text { en toneladas } \\
\text { métricas } \\
\end{array}$ & & & & & & & & & \\
\hline & $\begin{array}{l}\text { 5. Cobertura } \\
\text { de acueducto } \\
\text { urbano }\end{array}$ & & & & & & & & & \\
\hline & $\begin{array}{l}\text { 6.Cobertura de } \\
\text { alcantarillado } \\
\text { urbano }\end{array}$ & $96 \%$ & & PDD & & & $x$ & & & \\
\hline & $\begin{array}{l}\text { 7. Solución de } \\
\text { abastecimiento } \\
\text { de agua rural }\end{array}$ & & & & & & & & & \\
\hline & $\begin{array}{l}\text { 8. Solución de } \\
\text { saneamiento } \\
\text { básico rural }\end{array}$ & & & CRQ & $\begin{array}{l}00 \\
\text { unidades } \\
\text { rurales al } \\
09 \\
\end{array}$ & & & & & \\
\hline & $\begin{array}{l}\text { 9. Porcentaje } \\
\text { de hogares que } \\
\text { habitan en } \\
\text { acentamientos } \\
\text { precarios }\end{array}$ & & & & & & $x$ & & & $\begin{array}{l}\text { Reducir a } \\
4 \% \text { de } \\
\text { hogares }\end{array}$ \\
\hline
\end{tabular}

\section{A $\quad \mathbf{N}$}

Universidad Autónoma de Manizales 
En reforestación, la CRQ encuentra el obstáculo de propietarios que no permiten la reforestación de las cuencas de los ríos

Así mismo, la reforestación privada ha convertido el paisaje de montaña en extensos pinares sobre los que los ambientalistas han sensibilizado.

Para el ambiente la CRQ tiene metas en los términos del cuadro, pero no porcentualizadas.

En coberturas, el departamento responde a través de Esaquín. Los municipios no reportados corresponden al manejo en los municipios por empresas distintas. El cuadro siguiente presenta estado y cobertura para 8 de los 12 municipios:

\begin{tabular}{|c|c|c|c|c|c|c|c|c|}
\hline \multicolumn{9}{|c|}{ CAPACIDAD INSTALADA Y SU ESTADO AÑO 2007} \\
\hline Municipio & $\begin{array}{c}\text { Total } \\
\text { de } \\
\text { Redes }\end{array}$ & $\begin{array}{c}\text { Redes en } \\
\text { buen } \\
\text { Estado } \\
\text { ml }\end{array}$ & $\begin{array}{c}\text { Redes en } \\
\text { regular } \\
\text { y/o mal } \\
\text { estado } \\
\text { ml }\end{array}$ & $\begin{array}{c}\text { Redes } \\
\text { en } \\
\text { regular } \\
\text { y/o mal } \\
\text { estado } \\
\%\end{array}$ & $\begin{array}{c}\text { No. } \\
\text { Viviendas } \\
\text { casco } \\
\text { urbano } \\
\text { DANE } 2005\end{array}$ & $\begin{array}{c}\text { Acometidas } \\
\text { instaladas } \\
\text { urbano }\end{array}$ & $\begin{array}{c}\text { Cobertura } \\
\text { alcantarillado } \\
\text { (\%) }\end{array}$ & $\begin{array}{l}\text { Fuente } \\
\text { receptora }\end{array}$ \\
\hline Buenavista & 3.823 & 2.568 & 1.255 & $32,83 \%$ & 358 & 324 & $91 \%$ & $\begin{array}{l}\text { Q. La Picota y } \\
\text { Las Margaritas }\end{array}$ \\
\hline Circasia & 35.826 & 15.295 & 20.591 & $57,48 \%$ & 5.498 & 4.889 & $90 \%$ & $\begin{array}{c}\text { Q. Yeguas, } \\
\text { Cajones y } \\
\text { Teneria }\end{array}$ \\
\hline Filandia & 14.320 & 8.801 & 5.519 & $38,54 \%$ & 1.961 & 1.806 & $92 \%$ & $\begin{array}{l}\text { Q. San Jose, } \\
\text { Chorro de las } \\
\text { madres, El } \\
\text { Cacique }\end{array}$ \\
\hline Génova & 9.926 & 2.516 & 7.410 & $74,65 \%$ & 1.494 & 1.127 & $75 \%$ & $\begin{array}{c}\text { Río Gris y San } \\
\text { Juan }\end{array}$ \\
\hline La Tebaida & 50.320 & 27.070 & 23.250 & $46,20 \%$ & 7.528 & 7.000 & $93 \%$ & $\begin{array}{l}\text { Q. La Tulia y La } \\
\text { Jaramilla }\end{array}$ \\
\hline Montenegro & 52.381 & 27.965 & 24.416 & $46,61 \%$ & 7.908 & 6.678 & $84 \%$ & $\begin{array}{c}\text { Q. Cajones, } \\
\text { Animas y R. } \\
\text { Robles }\end{array}$ \\
\hline Quimbaya & 45.783 & 23.306 & 22.477 & $49,09 \%$ & 7.084 & 6.107 & $86 \%$ & $\begin{array}{l}\text { Q. Buenavista, } \\
\text { Agualinda, } \\
\text { Minarica, Rocio } \\
\text { y Valencia }\end{array}$ \\
\hline Salento & 11.755 & 7.810 & 3.945 & $33,56 \%$ & 1.103 & 977 & $89 \%$ & $\begin{array}{l}\text { Q. Mudo y La } \\
\text { Calzada }\end{array}$ \\
\hline TOTAL & 224.134 & 115.271 & 108.863 & $48,57 \%$ & 32.874 & 28.903 & $88 \%$ & \\
\hline
\end{tabular}

Fuente: Esaquin

Tomado de PDD.

EI PDD señala: "La Empresa Sanitaria del Quindío (ESAQUIN S.A. E.S.P) opera y administra los servicios de acueducto y alcantarillado en los municipios de Buenavista, Circasia, Filandia, Génova, La Tebaida, Montenegro, Quimbaya, Salento y Pijao, con una cobertura del $100 \%$ en acueducto y el $96 \%$ en alcantarillado.

En el municipio de Armenia ofrece el servicio de cueducto las Empresas Públicas de Armenia (EPA) y el servicio de aseo lo presta la empresa Servigenerales. En el municipio de Calarcá, lo realiza las Empresas Públicas de Calarcá y la empresa Multipropósito. En el municipio de Córdoba la empresa ESACOR".

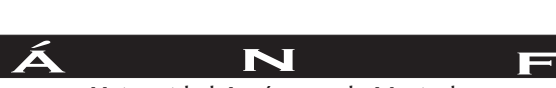




\begin{tabular}{|c|c|c|c|c|c|c|c|c|c|c|}
\hline & INDCADOR & $\begin{array}{l}\mid \text { ÍNEA } \\
\text { BASE }\end{array}$ & AÑ & RUENIE & META & $\begin{array}{l}\text { Eplicta } \\
\text { PDD }\end{array}$ & $\begin{array}{l}\text { Implíata } \\
\text { PDD }\end{array}$ & NOCONIEMPLADA & $\begin{array}{l}\text { INMERSÓN } \\
\text { POA }\end{array}$ & Neta/COMa2015 \\
\hline $\begin{array}{lr}\text { ODM } & 8 \\
\text { Fomertar una } \\
\text { dlianea } \\
\text { mundial para } \\
\text { eldesandlo }\end{array}$ & & & & & & & $\mathrm{x}$ & & & 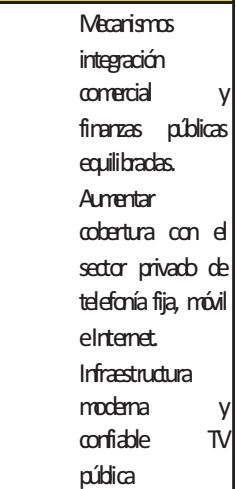 \\
\hline
\end{tabular}

La meta más sensible para los países en desigual posición en la estratificación y jerarquía mundial, y en consecuencia para sus poblaciones, se deja librada a "las buenas maneras de mesa", y ante falta de criterios expresos, al discurso oficial de las agencias y potencias sobre las virtudes de los modelos en que asientan su poder. En su versión nacional, se deja a la atractiva mano invisible de Smith dicho objetivo: “Mecanismos de integración comercial y finanzas públicas equilibradas. Con el sector privado aumentar coberturas de telefonía fija, móvil y de Internet. Infraestructura moderna y confiable para la transmisión de la televisión pública" (CONPES 091). La redistribución vendrá por obra y gracia en el tiempo, si diferido, es la lógica reverencial del mejor estado de cosas posible, o de "el mejor de los mundos posibles", que Voltaire, en su novela "Cándido" ofreciera como sociológica lectura hace más de 300 años, que en los términos de hoy sería la de relatos de anticipación, juego de espejos y espejismos.

La Gobernación por su parte impulsa el programa de redes y ha dispuesto toda una división para ello de conectividad virtual.

Por último, es necesario recabar sobre la concentración de recursos y oportunidades ya señalada en el Informe Regional de Desarrollo Humano, que se expresa como más positiva en la cercanía a las capitales de departamento y más negativa entre más distante, que se replica a su vez entre cabeceras y áreas rurales.

\section{Bibliografía}

ALVAREZ, Mario Alberto (Consultor). "PROMOCIÓN DEL DERECHO A LA EDUCACIÓN PÚBLICA, INCLUSIVA, GRATUITA Y DE CALIDAD EN EL DEPARTAMENTO DEL QUINDÍO", Fundación Luis Felipe Vélez, patrocinio de Save The Children, Reino Unido. CARTI LLA PARA MUNI CI PALI ZAR LOS OBJ ETIVOS DEL MI LENI O. GTZ CONPES SOCI AL No. 091. "Metas y estrategias de Colombia y los Objetivos del Milenio". DIAGNÓSTICO DE LA INFANCIA Y LA ADOLESCENCIA EN EL DEPARTAMENTO DEL QUINDío 2007. Anexo del Plan de Desarrollo, Departamento Administrativo de Planeación - Gobernación del Quindío.

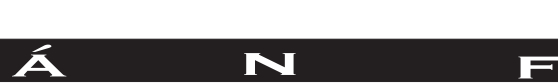


DOCUMENTOS PREPARATORIOS DEPARTAMENTO DEL QUINDÍO AL INFORME REGIONAL DE DESARROLLO HUMANO “UN PACTO POR LA REGIÓN". CEIR Universidad del Quindío, 2000 a 2002.

I NFORME REGIONAL DE DESARROLLO HUMANO “UN PACTO POR LA REGIÓN". PNUD 2004, Manizales.

LIBRO DEL MILENIO. "El desarrollo colombiano hacia los objetivos del milenio. Compromiso local con los objetivos. ...". GTZ; UNDP; Federación Colombiana de Municipios. Consultado el 05/09/2008.

(1998). "La cuestión agraria en Colombia a fines del milenio". El Áncora Editores, Bogotá.

MACHADO, ABSALÓN (1988). "El café, de la aparcería al capitalismo". Tercer Mundo Editores, Bogotá.

METAS DEL MI LENI O: RETROCESO PARA LAS MUJ ERES. Fuente: IPS. 05/09/2005. EI Portal de las Mujeres Latinoamericanas. En línea www.mujereshoy.com

MINISTERIO DE EDUCACIÓN NACIONAL. "Departamento del Quindío", diciembre de 2007, Bogotá.

OFFE, CLAUS (1994). "contradicciones en el Estado del Bienestar". Alianza Universidad, Madrid (1988).

PALACIOS, MARCO (1983). “El café en Colombia 1850 - 1870". El Colegio de México El Áncora Editores, México D.F. Bogotá.

PLAN DE DESARROLLO DEPARTAMENTAL “QUI NDÍ O UNI DO” 2008 - 2011. PROGRAMA PARA DEFINICIÓN DE LAS METAS DEL MILENIO EN LOS MUNICIPIOS COLOMBIANOS. GTZ, Olga Inés Sierra, Consultura.

VARIOS (2002). "La Reconstrucción Del Quindío, Lecturas Desde La Academia”, CEIR universidad del Quindío, Armenia. 